8-11-2020

\title{
Eco-Friendly Synthesis, Crystal Chemistry, and Magnetic Properties of Manganese-Substituted $\mathrm{CoFe}_{2} \mathrm{O}_{4} \mathrm{Nanoparticles}$
}

\author{
Sumayya M. Ansari \\ Kartik C. Ghosh \\ Missouri State University \\ Rupesh S. Devan \\ Debasis Sen \\ Pulya U. Sastry
}

See next page for additional authors

Follow this and additional works at: https://bearworks.missouristate.edu/articles-cnas

\section{Recommended Citation}

Ansari, Sumayya M., Kartik C. Ghosh, Rupesh S. Devan, Debasis Sen, Pulya U. Sastry, Yesh D. Kolekar, and C. V. Ramana. "Eco-Friendly Synthesis, Crystal Chemistry, and Magnetic Properties of ManganeseSubstituted CoFe2O4 Nanoparticles." ACS omega 5, no. 31 (2020): 19315-19330.

This article or document was made available through BearWorks, the institutional repository of Missouri State University. The work contained in it may be protected by copyright and require permission of the copyright holder for reuse or redistribution.

For more information, please contact BearWorks@library.missouristate.edu. 


\section{Authors}

Sumayya M. Ansari, Kartik C. Ghosh, Rupesh S. Devan, Debasis Sen, Pulya U. Sastry, Yesh D. Kolekar, and C. V. Ramana 


\section{Eco-Friendly Synthesis, Crystal Chemistry, and Magnetic Properties of Manganese-Substituted $\mathrm{CoFe}_{2} \mathrm{O}_{4}$ Nanoparticles}

Sumayya M. Ansari, Kartik C. Ghosh, Rupesh S. Devan, Debasis Sen, Pulya U. Sastry, Yesh D. Kolekar,* and C. V. Ramana*

Cite This: ACS Omega 2020, 5, 19315-19330

Read Online

\section{ACCESS}

Џlll Metrics \& More

| 回国 Article Recommendations

Supporting Information

ABSTRACT: The authors report on the effect of manganese $(\mathrm{Mn})$ substitution on the crystal chemistry, morphology, particle size distribution characteristics, chemical bonding, structure, and magnetic properties of cobalt ferrite $\left(\mathrm{CoFe}_{2} \mathrm{O}_{4}\right)$ nanoparticles (NPs) synthesized by a simple, cost-effective, and eco-friendly one-pot aqueous hydrothermal method. Crystal structure analyses indicate that the $\mathrm{Mn}$ (II)-substituted cobalt ferrites, $\mathrm{Co}_{1-x} \mathrm{Mn}_{x} \mathrm{Fe}_{2} \mathrm{O}_{4}$ (CMFO, $x=0.0-0.5$ ), were crystalline with a cubic inverse spinel structure (space group $\mathrm{Fd} 3 \mathrm{~m}$ ). The average crystallite size increases from 8 to $14 \mathrm{~nm}$ with increasing $\mathrm{Mn}$ (II) content; the crystal growth follows an exponential growth function while the lattice parameters follow Vegard's law. Chemical bonding analyses made using Raman spectroscopic studies further confirm the cubic inverse spinel phase. The relative changes in specific vibrational modes related to octahedral sites as a function of $\mathrm{Mn}$ content suggest a gradual change of measure of inversion of the ferrite lattice at nanoscale dimensions. Small-angle X-ray scattering and electron

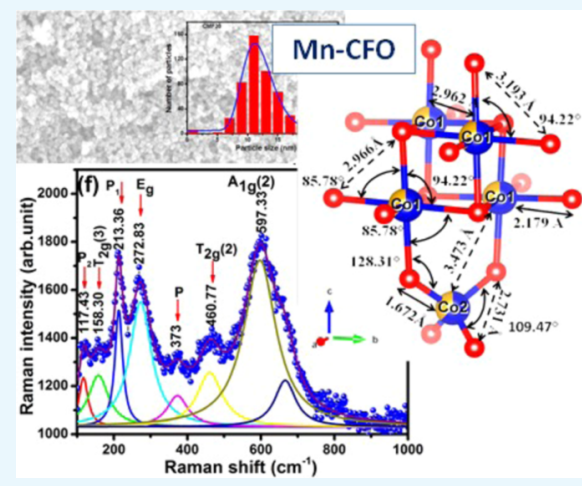
microscopy revealed a narrow particle size distribution with the spherical shape morphology of the CMFO NPs. The zero-fieldcooled and field-cooled magnetic measurements revealed the superparamagnetic behavior of CMFO NPs at room temperature. The sample with $x=0.3$ indicates a lower value of blocking temperature $(9.16 \mathrm{~K})$ with the improved (maximum) value of saturation magnetization. The results and the structure-composition-property correlation suggest that the economic, eco-friendly hydrothermal approach can be adopted to process superparamagnetic nanostructured magnetic materials at a relatively lower temperature for practical electronic and electromagnetic device applications.

\section{INTRODUCTION}

Spinel ferrites, which belong to the characteristic group of inorganic magnetic materials, have attracted a great deal of interest in view of their potential applications in various fields such as cell sorting, catalysis, ferrofluid applications, biosensors, magnetic resonance imaging (MRI), drug delivery, cellular signaling, hyperthermia, electronics, and biomedicine. $^{1-15}$ During the development of new technologies, spinel oxide-type materials are considered as competent materials due to their extraordinary physical, chemical, electronic, and magnetic properties. ${ }^{11}$ Magnetic nanoparticles (MNPs), especially nanoferrites with the chemical formula $\mathrm{MFe}_{2} \mathrm{O}_{4}$ ( $\mathrm{M}=\mathrm{Co}, \mathrm{Zn}, \mathrm{Ni}, \mathrm{Mn}$, etc.), exhibit remarkable properties, which contrast to their bulk behavior. Among different spineltype ferrite systems, manganese ferrite $\left(\mathrm{MnFe}_{2} \mathrm{O}_{4}\right)$ and cobalt ferrite $\left(\mathrm{CoFe}_{2} \mathrm{O}_{4}\right.$; CFO) NPs received special consideration as alternatives to magnetite $\left(\mathrm{Fe}_{3} \mathrm{O}_{4}\right) \mathrm{NPs}$ due to their chemical inertness to oxidation and inherent magnetic properties. ${ }^{16}$ Specifically, inverse spinel CFO is one of the most industrially important members of the magnetic ferrite class for device applications. ${ }^{17} \mathrm{CoFe}_{2} \mathrm{O}_{4}$ is the preferred choice for large data storage and usage in physical (stress) sensors because of higher coercive field and magnetocrystalline anisotropy. ${ }^{17,18}$ On the other hand, $\mathrm{CFO}$ and $\mathrm{MnFe}_{2} \mathrm{O}_{4}$ are becoming important for biomedical applications (magnetic resonance imaging, biomolecule detection, and magnetic hyperthermia) due to their increased degree of magnetization compared to other nanoferrites. ${ }^{18-24}$ The requirements of these applications are achieved by tailoring of the NPs' magnetic properties, which are known to radically depend on several chemical and physical characteristics, such as particle size, chemical composition, cation distribution, preparation method, surface properties, and interparticle interactions. In this context, the possibility of changing the characteristics of the $\mathrm{M}$ (II) cation within the spinel ferrite is a key to modify magnetic properties. Recently, partial $\mathrm{M}(\mathrm{II})$ substitution within these nanoferrites ( $\mathrm{Co}_{x} \mathrm{M}_{1-x} \mathrm{Fe}_{2} \mathrm{O}_{4}$ with $x=0-1$ ) has become prominent to improve their performance. ${ }^{11}$ The potential of this strategy has been highlighted to improve the structure and magnetic

Received: August 5, 2019

Accepted: January 17, 2020

Published: July 30, 2020 
properties for the preparation of other ferrites, for example, $\mathrm{Zn}_{x} \mathrm{Mn}_{1-x} \mathrm{Fe}_{2} \mathrm{O}_{4}, \mathrm{Zn}_{x} \mathrm{Fe}_{1-x} \mathrm{Fe}_{2} \mathrm{O}_{4}{ }^{23} \mathrm{Ni}_{1-x} \mathrm{Zn}_{x} \mathrm{Fe}_{2} \mathrm{O}_{4}{ }^{25}$ etc.

It is important to note that, among the many applications of nanoferrites, biomedical applications are particularly interesting and widespread. Essentially, for the biomedical applications, superparamagnetic behavior at room temperature, high saturation magnetization, and size within the $1-50 \mathrm{~nm}$ range are desirable. ${ }^{26}$ Nevertheless, developing superparamagnetic $\mathrm{Co}(\mathrm{II})$ - and $\mathrm{Mn}$ (II)-based ferrite NPs with required properties (structure, magnetic, and electrical) to meet the given application is challenging. Various synthesis methods have been reported for obtaining $\mathrm{Co}_{x} \mathrm{Mn}_{1-x} \mathrm{Fe}_{2} \mathrm{O}_{4}$ mixed ferrites, such as the co-precipitation process, ${ }^{11}$ ceramic processing, ${ }^{27}$ heating of layered double-hydroxide precursors, $^{28}$ thermal decomposition, ${ }^{29}$ sol-gel method, ${ }^{30}$ chemical autocombustion, ${ }^{31}$ the polyol method, ${ }^{32}$ and the hydrothermal route. ${ }^{3,34}$ However, most of these synthetic routes require special processing and/or unusual inputs (high temperatures, organic solvents, and postsynthesis treatments), which often results in Co-Mn ferrites with considerably higher particle size and ferromagnetic properties. Thus, the synthesis of superparamagnetic monodisperse MNPs at a lower temperature to avoid particle growth becomes the most compelling and challenging task. Additionally, the design and development of efficient methods for the synthesis of high-quality $\mathrm{Co}_{x} \mathrm{Mn}_{1-x} \mathrm{Fe}_{2} \mathrm{O}_{4}$ for a broad range of electronic, magnetic, and electromagnetic applications continue to be an active area of research. Therefore, motivated by these scientific challenges, in the present work, an attempt has been made to synthesize $\mathrm{Co}_{1-x} \mathrm{Mn}_{x} \mathrm{Fe}_{2} \mathrm{O}_{4} \quad(x=0.0-0.5$; CMFO $)$ NPs through an innovative, simple, economic, and eco-friendly one-pot aqueous hydrothermal route. Notably, compared to other conventional methods, the hydrothermal synthesis route is a simple one with a high rate of reaction while maintaining a low operating temperature, resulting in uniform size distribution. This method is easily scalable to industrial applications. Furthermore, as reported in this paper, synthesis of CMFO NPs without any surfactant or capping agent by the wellrecognized green approach, which is based on an aqueous medium that is easier to conduct, is interesting for fundamental scientific reasons. To the best of our knowledge, while only limited or few studies exist on the $\mathrm{Co}_{x} \mathrm{Mn}_{1-x} \mathrm{Fe}_{2} \mathrm{O}_{4}$ mixed ferrites prepared by the hydrothermal process, control over nanoparticle dimensions and maintaining the crystal chemistry are still major limitations to overcome. Also, in most of the cases, the nanostructured CMFO is characterized by the agglomerated morphology and ferromagnetic behavior. In this context, our approach to control the microstructure, magnetism, and the degree of inversion of nanoferrites through a progressive variation of $\mathrm{Mn}$ (II) cation in the CMFO system may have numerous scientific and technological benefits, specifically since MNPs with superparamagnetic behavior at room temperature are preferred for MRI, ${ }^{35}$ hyperthermia, ${ }^{36}$ and drug-delivery ${ }^{37}$ applications. Thus, chemical engineering of the CMFO NPs through the chemical substitution allows designing materials with controlled structure, morphology, and magnetism for integration into technological applications.

\section{EXPERIMENTAL SECTION}

Synthesis. Materials and Reagents. Manganese(II) nitrate tetrahydrate $\left(\geq 99 \%, \mathrm{Mn}\left(\mathrm{NO}_{3}\right)_{2} \cdot 4 \mathrm{H}_{2} \mathrm{O}\right)$, cobalt nitrate hexahydrate $\left(\geq 99 \%, \mathrm{Co}\left(\mathrm{NO}_{3}\right)_{2} \cdot 6 \mathrm{H}_{2} \mathrm{O}\right)$, and ferric nitrate nonahydrate $\left(\geq 99 \%, \mathrm{Fe}\left(\mathrm{NO}_{3}\right)_{3} \cdot 9 \mathrm{H}_{2} \mathrm{O}\right)$ were used as the manganese, cobalt, and iron precursors, respectively, while an ammonia solution (25\%) was employed as a precipitant agent. All of the analytical grade reagents were used as received from Sigma-Aldrich without further purification.

Processing of CMFO Nanoparticles. The CMFO $(x=0.00$, $0.15,0.25,0.30,0.40$, and 0.50$)$ samples were prepared by a simple hydrothermal approach. During the preparation, stoichiometric (mixture) amounts of metal salts ( $\mathrm{Co}+$ $\mathrm{Mn}): \mathrm{Fe}$ as $1: 2$ ) were added to deionized (DI) water and stirred well. Then, the $\mathrm{pH}$ of the solution was adjusted to 12 by adding the ammonia solution drop by drop to make the total solution volume $2 / 3$ of the total volume of the autoclave (250 $\mathrm{mL})$. After that, the solution mixture was treated under hydrothermal conditions at $130{ }^{\circ} \mathrm{C}$ for $24 \mathrm{~h}$. The prepared particles were separated by centrifuging the final solution with DI water and ethanol several times. The resulting black precipitates were dried in an oven at $100{ }^{\circ} \mathrm{C}$ overnight. The CMFO NPs with $x$ values of $0.00,0.15,0.25,0.30,0.40$, and 0.50 were denoted as CF, CMF15, CMF25, CMF30, CMF40, and CMF50, respectively. Finally, the as-prepared powder was used for further characterization without subsequent sintering.

Characterization. X-ray Diffraction (XRD). Crystallographic studies of CMFO NPs were carried out using an Xray powder diffractometer (D8-Advanced Bruker) with $\mathrm{Cu} \mathrm{K} \alpha$ radiation $(\lambda=1.5406 \AA)$. The powder sample was scanned slowly over a $2 \theta$ range of $20-80^{\circ}$ at a scanning rate of $4^{\circ}$ $\mathrm{min}^{-1}$. The detailed structural characterization was performed with the Rietveld method. To generate theoretical X-ray diffraction patterns, we have used the ICSD data with collection code as: 109044. Finally, the crystal structure is modeled using VESTA software to represent the bond angle, bond length, and interaction between the octahedral and tetrahedral sites for CMFO NPs, as derived from the XRD refinement data.

Raman Spectroscopy. Raman studies were performed on an InVia Micro-Raman (Renishaw) spectrophotometer with $532 \mathrm{~nm}$ laser excitation.

Field Emission Scanning Electron Microscopy (FE-SEM). Field emission scanning electron microscopy (FE-SEM, Karl ZEISS JEOL) was used to analyze the surface morphology and particle size distribution. The size distribution of NPs was estimated by the image analysis of micrographs using Image software. Energy-dispersive X-ray spectrometry (EDS) measurements were used for the compositional analysis of pristine NPs.

Small-Angle X-ray Scattering (SAXS). The SAXS measurements were carried out using a Rigaku small-angle goniometer mounted on a rotating anode X-ray generator. The scattered Xray intensity $I(q)$ was recorded using a scintillation counter with a pulse height analyzer by varying the scattering angle $2 \theta$, where $q$ is the scattering vector given by $4 \pi \sin (\theta) / \lambda$, where $\lambda$ is the wavelength of incident $(\mathrm{Cu} \mathrm{K} \alpha) \mathrm{X}$-rays. The intensities were corrected for sample absorption and smearing effects of collimating slits.

Magnetic Measurements. Magnetization was measured as a function of temperature (from 5 to $300 \mathrm{~K}$ ) and magnetic field $(-50$ to $+50 \mathrm{kOe})$ using a superconducting quantum interference device magnetometer. The zero-field-cooling (ZFC) and field-cooling (FC) measurements were carried out in the temperature range of $5-300 \mathrm{~K}$ at a 100 Oe magnetic field. 

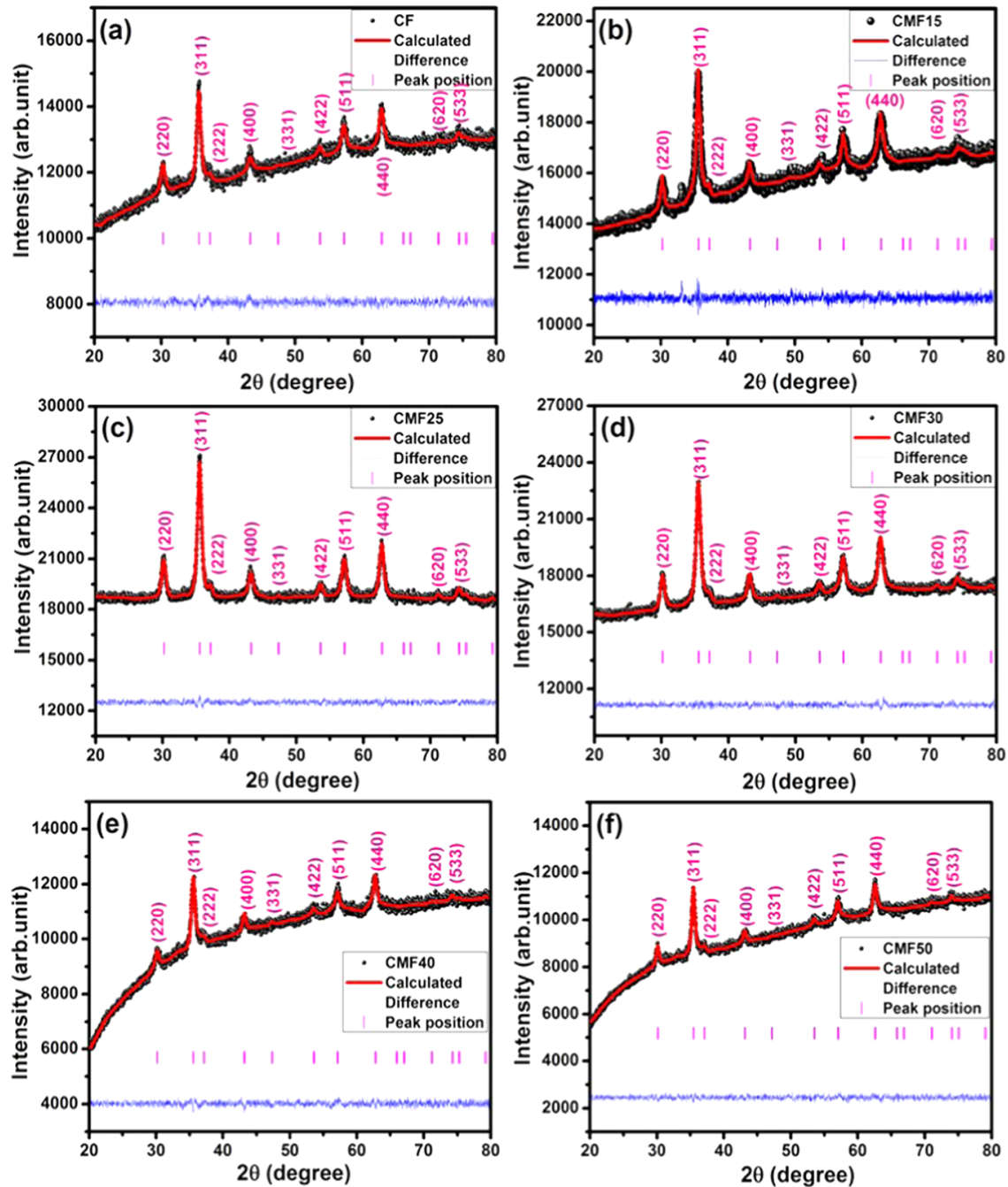

Figure 1. Experimental XRD patterns of (a) CF, (b) CMF15, (c) CMF25, (d) CMF30, (e) CMF40, and (f) CMF50 NPs. Rietveld refinement data are also shown.

Table 1. Structural and Refined Parameters of CMFO Obtained from Rietveld Refinement of XRD Data

\begin{tabular}{|c|c|c|c|c|c|c|c|}
\hline sample & $\begin{array}{l}\text { average crystallite size } \\
\quad(\mathrm{nm})( \pm 0.15)\end{array}$ & $\begin{array}{l}\text { lattice parameter }(a, \\
\AA)( \pm 0.015)\end{array}$ & $\begin{array}{l}\text { volume of unit cell } \\
\qquad\left(V, \mathrm{~nm}^{3}\right)\end{array}$ & $\begin{array}{l}\text { oxygen positional } \\
\text { parameter }(u, \AA)\end{array}$ & $\begin{array}{c}\text { weighted } \\
\text { pattern } R_{\mathrm{wp}}(\%)\end{array}$ & $\begin{array}{c}\text { expected factor } \\
R_{\text {exp }}(\%)\end{array}$ & $\begin{array}{l}\text { goodness of fit } \\
(\mathrm{GoF})\left(\chi^{2}\right)\end{array}$ \\
\hline CF & 08.02 & 8.3546 & 0.583 & 0.2582 & 32.10 & 31.66 & 1.03 \\
\hline CMF15 & 08.19 & 8.3644 & 0.585 & 0.2430 & 31.00 & 28.66 & 1.17 \\
\hline CMF25 & 10.54 & 8.3761 & 0.588 & 0.2597 & 15.90 & 15.06 & 1.12 \\
\hline CMF30 & 09.91 & 8.3816 & 0.589 & 0.2589 & 19.80 & 18.86 & 1.11 \\
\hline CMF40 & 11.64 & 8.3776 & 0.588 & 0.2598 & 43.20 & 41.52 & 1.08 \\
\hline CMF50 & 13.74 & 8.3949 & 0.592 & 0.2598 & 36.20 & 34.58 & 1.09 \\
\hline
\end{tabular}

\section{RESULTS AND DISCUSSION}

Crystal Chemistry and Chemical Bonding. X-ray Diffraction. Figure 1 shows the X-ray diffraction patterns and the Rietveld refinement data for CMFO samples. The Bragg reflections match with both the peak positions and relative intensities of those reported for bulk ferrite standards, ${ }^{11,27,33}$ confirming the expected cubic spinel structure (JCPDS Card No. 22-1086 space group: Fd3m (227)). However, the CMF15 sample consists of an additional, weak peak at $2 \theta=33.40^{\circ}$, which corresponds to the hematite phase, $\mathrm{Fe}_{2} \mathrm{O}_{3}$ (JCPDS card no. 33-0664). No secondary peaks are detected in the XRD data for other samples, indicating the single-phase formation. Hence, replacing Mn(II) by Co(II) or the lower synthesis temperature $\left(130^{\circ} \mathrm{C}\right)$ changes the crystal symmetry of CMFO NPs. The structural parameters obtained from the refinement are listed in Table 1 . The diffraction maxima observed for each sample are broadly intense, which implies the highly nanocrystalline nature of the CMFO samples. Moreover, it is observed that the lattice parameter " $a$ " of the CFMO sample increases with increasing $\mathrm{Mn}$ (II) concentration. This is similar to the behavior reported for their bulk counterparts (8.499 $\AA$ for $\mathrm{MnFe}_{2} \mathrm{O}_{4}$, JCPDS card no. 100319 and $8.392 \AA$ for $\mathrm{CoFe}_{2} \mathrm{O}_{4}, \mathrm{JCPDS}$ card no. 22-1086). The variation of $a$ with $x(\mathrm{Mn})$, as shown in Figure 2a, exhibits a linear behavior following Vegard's law. ${ }^{38}$ This linear trend following Vegard's law can be assigned to the gradual replacement of $\mathrm{Mn}(\mathrm{II})$ ions having a larger ionic radius 

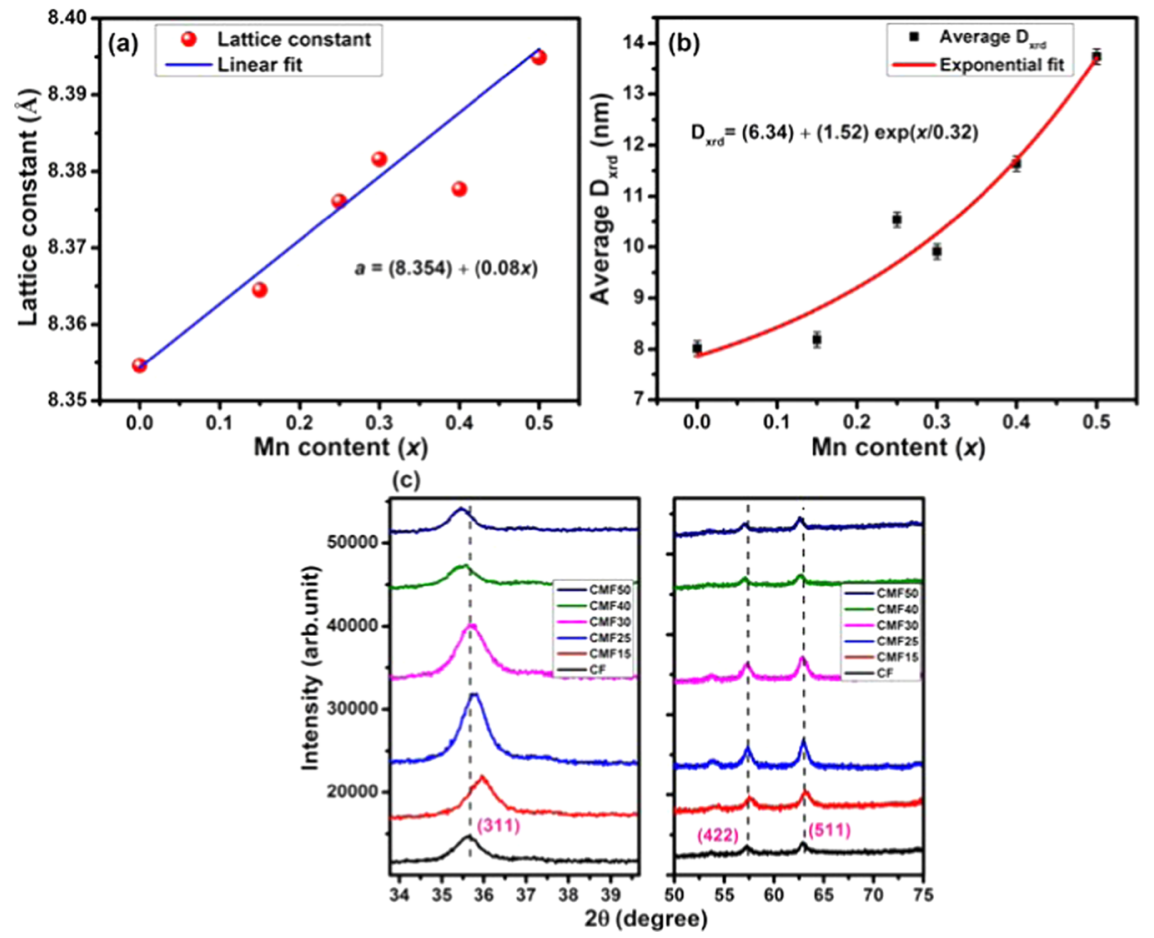

Figure 2. Effect of $\mathrm{Mn}$ concentration on (a) lattice parameter and (b) average crystallite size of $\mathrm{Co}_{1-x} \mathrm{Mn}_{x} \mathrm{Fe}_{2} \mathrm{O}_{4} \mathrm{NPs}$. (c) XRD patterns of $\mathrm{Co}_{1-x} \mathrm{Mn}_{x} \mathrm{Fe}_{2} \mathrm{O}_{4}$ nanoparticles in the $2 \theta$ range of $34-40^{\circ}$ and $50-75^{\circ}$. The data highlight the shift of (311), (422), and (511) Bragg reflections to lower $2 \theta$ with increasing $\mathrm{Mn}(\mathrm{II})$ content.

$(0.83 \AA)$ by the smaller Co(II) cations $(0.78 \AA) .{ }^{39-41}$ Notably, it is seen that the most intense (311) peak position shifts systematically to the lower $2 \theta$ value except for the sample CMF15. Thus, for a lower value of $x \leq 0.15$, although the $\mathrm{Mn}$ expected to occupy the octahedral site, some of the Co from the octahedral site are migrated to the tetrahedral site, resulting in the positive (311) peak shift for the CMF15 sample. The peak shift is also noted for the (422) and (511) peaks (Figure 2c).

The average crystallite size $\left(D_{\mathrm{XRD}}\right)$ values (Table 1 and Figure $2 \mathrm{~b}$ ) confirm that the size variation follows an exponential growth with $x(\mathrm{Mn})$. The $D_{\mathrm{XRD}}-x(\mathrm{Mn})$ data were modeled (Figure $2 \mathrm{~b}$ ) using an exponential growth function $^{42}$

$$
D(x)=D^{\prime}+A \exp ^{x / x_{c}}
$$

where $D^{\prime}$ is the smaller crystallite size, which can be achieved, in the present study, up to $\sim 6 \mathrm{~nm}$, and the initial value is represented by " $A$ ". The growth profile can be expressed by the magnitude of growth rate $\left(x_{c}\right)$ (here, $x_{c} \sim 0.33$ ), which represents the influence of the $\mathrm{Co}$ (II)/ $\mathrm{Mn}$ (II) molar ratio on the size of CMFO NPs. This finding is interesting and helps to decide that the $\mathrm{Co}$ (II)/ $\mathrm{Mn}$ (II) molar ratio is inherently responsible for change of average crystallite size, irrespective of the preparation methods and parameters. Thus, the identification of $D\left(D^{\prime}, A, x_{c}\right)$ depending on the function of " $x$ " allows accurate management of particle size experimentally, by selecting the optimum $\mathrm{Co}(\mathrm{II}) / \mathrm{Mn}$ (II) combination during the hydrothermal process.

To better understand the effect of $\mathrm{Mn}$ (II) substitution with $\mathrm{Co}$ (II) in CMFO and the role of $\mathrm{Mn}$ (II) ions, the bond angle and bond lengths are determined using the Rietveld method. While performing the Rietveld refinement on the samples, we have considered the following points: (i) All possible cation arrangements with 0.001 stoichiometry sensitivity that $\mathrm{Co}, \mathrm{Fe}$ ions can occupy both the tetrahedral and octahedral sites and Mn ions occupy only octahedral site are considered, (ii) the oxygen positional parameter was chosen initially to be 0.25 and then refined, (iii) for the agreement of calculated and experimental intensity ratios, the differences of calculated and experimental intensities for all of the distribution cases are considered and the sum of these differences is minimized and refined until convergence is reached. Note that the refinement of diffraction data predicts deviation from the ideal inverse cation distribution by transferring some of $\mathrm{Co}^{+2}$ from octahedral (B) site to tetrahedral (A) site for all of the samples. A close view of the structure around the tetrahedral and octahedral sites along with the observed bond angles and bond length is presented in Figure S1. It is evident from the observed angles at the tetrahedral and octahedral sites that each CMFO NP is stabilized in the cubic structure with almost no local distortion at the tetrahedral site although a local distortion at the octahedral site is observed compared to the standard bond angle values for the spinel structure. Figure S1 shows the $\mathrm{O}-\mathrm{Co} 2-\mathrm{O}(\mathrm{O}-\mathrm{Fe} 2-\mathrm{O})$ angles, which match with the angle of the ideal spinel value $109.47^{\circ}$ for all of the CMFO NPs. However, there is a slight local distortion observed at the octahedral site for CMFO NPs; the $\mathrm{O}-\mathrm{Co} 1-\mathrm{O}$ bond angle (ideal value, $90^{\circ}$ ) deviates to $86.43,86.81,85.78,86.13,85.78$, and $85.78^{\circ}$, which are opposed to the $\mathrm{O}-\mathrm{Fe} 1-\mathrm{O}$ bond angles of $93.57,93.19,94.22,93.87,94.22$, and $94.22^{\circ}$ for the CF, CMF15, CMF25, CMF30, CMF40, and CMF50 samples, respectively. In addition, the most important $\mathrm{Co} 1-\mathrm{O}-\mathrm{Fe} 2$ ( $\mathrm{Co} 1-\mathrm{O}-\mathrm{Co} 2, \mathrm{Fe} 1-\mathrm{O}-\mathrm{Co} 2, \mathrm{Fe} 1-\mathrm{O}-\mathrm{Fe} 2)$ bond angles (ideal value, $125^{\circ}$ ) are critically analyzed for all of the samples and the values are found to be 127.83, 123.04, 128.31, 128.05, 128.31 , and $128.31^{\circ}$, respectively, for CMFO samples. It shows a deviation of about $\sim 2.83,-1.96,3.31,3.05,3.31$, and $3.31^{\circ}$, 
Table 2. Bond Angle and Bond Length Extracted from Rietveld Refinement

\begin{tabular}{|c|c|c|c|c|c|c|c|c|c|c|c|c|c|}
\hline \multirow{2}{*}{$\begin{array}{l}\text { bond angle } \\
\text { type }\end{array}$} & \multicolumn{6}{|c|}{ bond angle $\left({ }^{\circ}\right)$} & \multirow[b]{2}{*}{ bond type } & \multicolumn{6}{|c|}{ bond length $(\AA)$} \\
\hline & $\mathrm{CF}$ & CMF15 & CMF25 & CMF30 & CMF40 & CMF50 & & $\mathrm{CF}$ & CMF15 & CMF25 & CMF30 & CMF40 & CMF50 \\
\hline \multirow[t]{3}{*}{$\mathrm{CoI}-\mathrm{O}-\mathrm{Co} 2$} & 127.83 & 123.04 & 128.31 & 128.05 & 128.31 & 128.31 & $d_{12}=\mathrm{Col}-\mathrm{O}$ & 2.160 & 2.037 & 2178 & 2.173 & 2179 & 2.184 \\
\hline & & & & & & & $d_{23}=\mathrm{O}-\mathrm{Fe} 2$ & 1.691 & 1.908 & 1672 & 1.685 & 1672 & 1.676 \\
\hline & & & & & & & $\begin{array}{l}d_{13}= \\
\quad \mathrm{Col}-\mathrm{Fe} 2\end{array}$ & 3.466 & 3.468 & 3473 & 3.475 & 3473 & 3.480 \\
\hline \multirow[t]{3}{*}{$\mathrm{O}-\mathrm{Co} 2-\mathrm{O}$} & 109.47 & 109.47 & 109.47 & 109.47 & 109.47 & 109.47 & $d_{12}=\mathrm{O}-\mathrm{Co} 2$ & 1.691 & 1.908 & 1672 & 1.685 & 1672 & 1.676 \\
\hline & & & & & & & $d_{23}=\mathrm{Co} 2-\mathrm{O}$ & 1.691 & 1.908 & 1672 & 1.685 & 1672 & 1.676 \\
\hline & & & & & & & $d_{13}=\mathrm{O}-\mathrm{O}$ & 2.762 & 3.116 & 2.730 & 2.752 & 2.731 & 2.736 \\
\hline \multirow[t]{3}{*}{$\mathrm{O}-\mathrm{Col}-\mathrm{O}$} & 86.43 & 86.81 & 85.78 & 86.13 & 85.78 & 85.78 & $d_{12}=\mathrm{O}-\mathrm{Col}$ & 2.160 & 2.037 & 2.179 & 2.173 & 2.179 & 2.184 \\
\hline & & & & & & & $d_{23}=\mathrm{Col}-\mathrm{O}$ & 2.160 & 2.037 & 2.179 & 2.173 & 2.179 & 2.184 \\
\hline & & & & & & & $d_{13}=\mathrm{O}-\mathrm{O}$ & 2.959 & 2.799 & 2.965 & 2.967 & 2.966 & 2.973 \\
\hline \multirow[t]{3}{*}{$\mathrm{O}-\mathrm{Col}-\mathrm{O}$} & 93.57 & 94.22 & 94.22 & 93.87 & 94.22 & 94.22 & $d_{12}=\mathrm{O}-\mathrm{Col}$ & 2.160 & 2.037 & 2.179 & 2.173 & 2.179 & 2.184 \\
\hline & & & & & & & $d_{23}=\mathrm{Col}-\mathrm{O}$ & 2.160 & 2.037 & 2.179 & 2.173 & 2.179 & 2.184 \\
\hline & & & & & & & $d_{13}=\mathrm{O}-\mathrm{O}$ & 3.149 & 2.9593 & 3.193 & 3.175 & 3.193 & 3.200 \\
\hline
\end{tabular}

Table 3. Cation Distribution Obtained from the Refinement of X-ray Diffraction Data

$\begin{array}{ll}\text { sample code } & \text { sample formula } \\ \text { CF } & \mathrm{CoFe}_{2} \mathrm{O}_{4} \\ \text { CMF15 } & \mathrm{Co}_{0.85} \mathrm{Mn}_{0.15} \mathrm{Fe}_{2} \mathrm{O}_{4} \\ \text { CMF25 } & \mathrm{Co}_{0.75} \mathrm{Mn}_{0.25} \mathrm{Fe}_{2} \mathrm{O}_{4} \\ \text { CMF30 } & \mathrm{Co}_{0.70} \mathrm{Mn}_{0.30} \mathrm{Fe}_{2} \mathrm{O}_{4} \\ \text { CMF40 } & \mathrm{Co}_{0.60} \mathrm{Mn}_{0.40} \mathrm{Fe}_{2} \mathrm{O}_{4} \\ \text { CMF50 } & \mathrm{Co}_{0.50} \mathrm{Mn}_{0.50} \mathrm{Fe}_{2} \mathrm{O}_{4}\end{array}$

respectively, for the CF, CMF15, CMF25, CMF30, CMF40, and CMF50 samples as the ideal value is $125^{\circ}$. Thus, a deviation in bond angle indicates buckling of the $\mathrm{FeO}_{6}$ and $\mathrm{CoO}_{6}$ octahedra as the size increases with increasing $x(\mathrm{Mn})$ in CMFO. Note that, with increasing Mn content, all of the samples (except CMF15) show an increase in the Co1-O$\mathrm{Fe} 2$ and $\mathrm{Fe} 1-\mathrm{O}-\mathrm{Fe} 2$ bond angle values. This clearly indicates that the substitution of Co with $\mathrm{Mn}$ enhances the well-known $\mathrm{A}-\mathrm{B}$ interaction. Table 2 and Figure $\mathrm{S} 1$ show the bond lengths observed for octahedral and tetrahedral sites, intercation distances, and (cation) $)_{\text {oct }}-$ oxygen-(cation $)_{\text {tet }}$ distances. It is observed that the value of the $\mathrm{Co} 1-\mathrm{O}$ bond length increases at the octahedral site, whereas the value of the $\mathrm{O}-\mathrm{Co} 2$ bond length decreases at the tetrahedral site with an increase of $\mathrm{Mn}$ substitution compared to the pure CF sample. It has been reported that the theory of superexchange does not give a dependence of the strength of interaction on the distances. Therefore, the dumbbell shape of the $2 p$ orbital makes it a reasonable assumption that the interaction for a given ionic separation will be larger when the angle of metal ion-oxygenmetal ion is $180^{\circ}$ and will be very small when this angle is $90^{\circ}$. With these two assumptions, an examination of the ionic distribution in the ferrite lattice leads to the conclusion that the $\mathrm{A}-\mathrm{B}$ interaction is relatively strong, the $\mathrm{A}-\mathrm{A}$ interaction is very weak, and the $B-B$ interaction is probably intermediate between these two extremes. ${ }^{43}$ The experimentally observed variation of magnetic moment with $x(\mathrm{Mn})$ is thus qualitatively understood by the assumption that the Mn cation occupies only the octahedral site, and as the Mn content increases, the slight or relative number of Co ions are expected to migrate from the octahedral to tetrahedral site. This migration is more dominant in CMF15, thus causing the A-B interaction to be reduced. In addition, the number of $\mathrm{Co}$ cations migrated from the octahedral to tetrahedral site is relatively controlled or observed to be less when $x=0.25$ and 0.30. Thus, the enhanced value of magnetization is observed for CMF25 and CMF30 and is in agreement with the bulk ferrite. Cation distribution for these ferrites has been proposed on the basis of saturation magnetization measurements. In the present study, the occupancy of cobalt ions at the tetrahedral site has been chosen so as to provide the better possible cationic distribution agreeable to the experimentally observed value of magnetization. Table 3 shows the possible cation distribution obtained from the refinement, which well agreed with the experimental magnetic moment. Therefore, (i) an exponential increase in the average crystallite size, (ii) a linear increase in the lattice parameter, (iii) the absence of local distortion at the tetrahedral site, (iv) the presence of local octahedral distortion at the octahedral site, and (v) the enhanced value of (cation) $)_{\text {oct }}-$ oxygen-(cation) tet bond angles are the structural characteristic results of the Mn substitution in CMFO MNPs.

Raman Spectroscopy. To gain deeper insights into the crystal structure and chemical bonding, Raman spectroscopy is used to characterize CMFO NPs. It helps to identify the features of all of the CMFO NPs and is an important tool to get the details of NPs' internal structure and chemical bonding. Furthermore, Raman spectroscopy is one of the effective and nondestructive techniques to differentiate spinel compounds according to their type (normal, inverse and mixed). ${ }^{15,44}$ Moreover, when the corresponding XRD patterns are similar, Raman spectroscopy and/or Mössbauer spectroscopy can be used for the structural characterization of spinel-type nanomaterials. ${ }^{45}$ In the current study, we have used Raman spectroscopy to check the presence of noncrystalline secondary phases, which may not be identified in XRD studies (as the nanoferrites are synthesized at lower temperatures). Figure 3 shows the Raman spectra of CMFO MNPs. Due to the smaller size, some weak Raman modes and peak broadening are observed. Hence, to perform an accurate analysis, all of the spectra were deconvoluted, and the results are presented in 

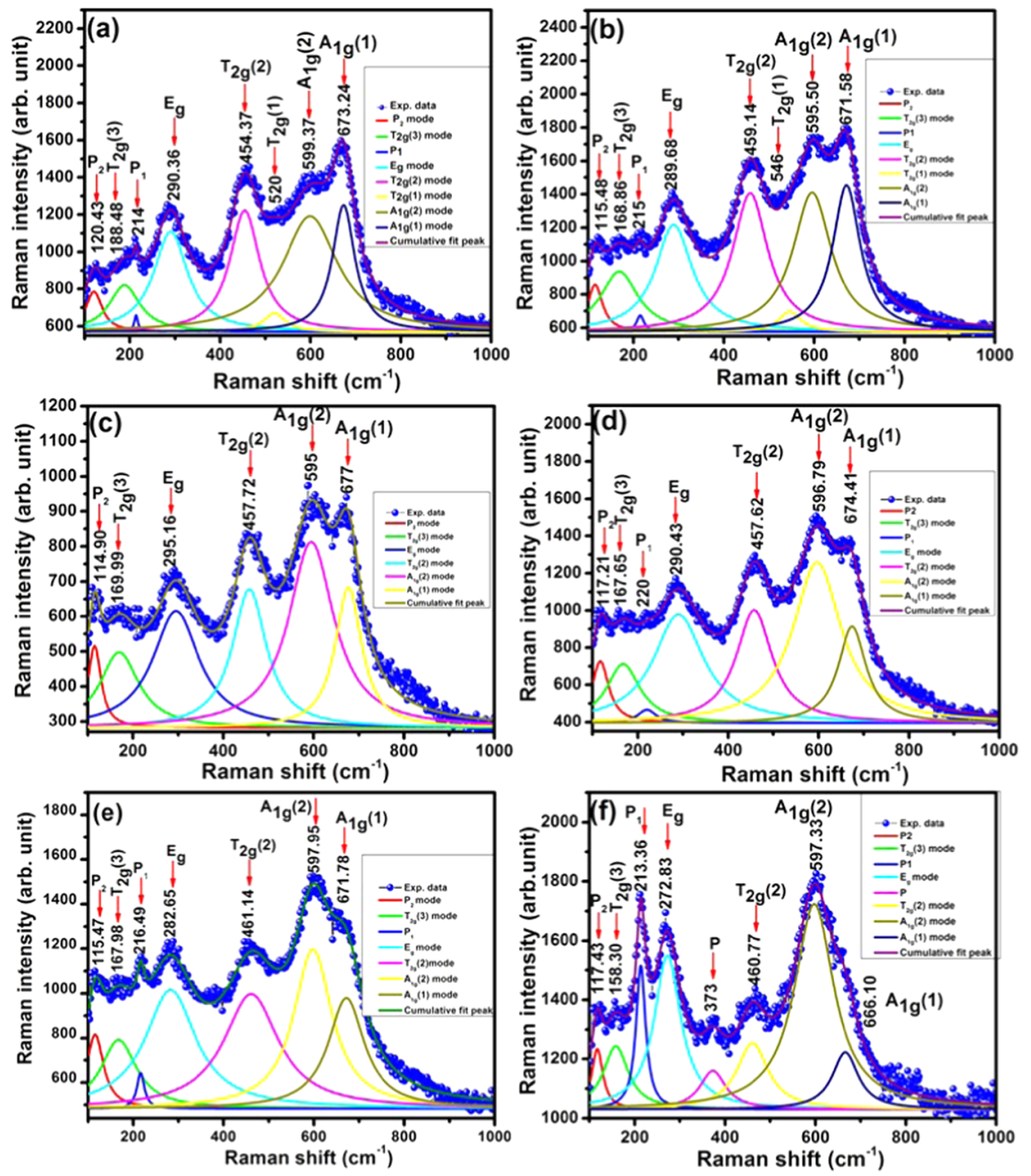

Figure 3. Deconvoluted Raman spectra for (a) CF, (b) CMF15, (c) CMF25, (d) CMF30, (e) CMF40, and (f) CMF50 NPs.

Table S1 (Supporting Information). All of the spectra exhibit five Raman-active phonon modes, which are characteristic of ferrites $^{15}$ with a spinel $(F d 3 m)$ structure: $A_{1 g}(1)(666-677$ $\left.\mathrm{cm}^{-1}\right), \mathrm{A}_{1 \mathrm{~g}}(2)\left(595-599 \mathrm{~cm}^{-1}\right), 3 \mathrm{~T}_{2 \mathrm{~g}}(520-546,454-460$, and $\left.151-188 \mathrm{~cm}^{-1}\right)$, and $\mathrm{E}_{\mathrm{g}}\left(271-373 \mathrm{~cm}^{-1}\right) .{ }^{44,46}$ It has been reported that the cubic spinel compounds exhibit five Ramanactive modes, namely, $\mathrm{A}_{1 \mathrm{~g}}, 3 \mathrm{~T}_{2 \mathrm{~g}}$, and $\mathrm{E}_{\mathrm{g}}{ }^{47}$ Moreover, in the Raman spectra of cubic spinel ferrites, an additional $A_{1 g}$ active mode (designated as the $\mathrm{A}_{1 \mathrm{~g}}(2)$ mode) is observed as a shoulder at a lower wavenumber, which is a typical feature of inverse as well as mixed spinels. The order of observed energies of these Raman-active modes is: $\mathrm{A}_{1 \mathrm{~g}}(1)>\mathrm{A}_{1 \mathrm{~g}}(2)>\mathrm{T}_{2 \mathrm{~g}}(1)>$ $\mathrm{T}_{2 \mathrm{~g}}(2)>\mathrm{E}_{\mathrm{g}}>\mathrm{T}_{2 \mathrm{~g}}(3){ }^{48}$ According to the literature, for $\mathrm{CoFe}_{2} \mathrm{O}_{4}$, peaks to the $\mathrm{E}_{\mathrm{g}}$ and $3 \mathrm{~T}_{2 \mathrm{~g}}$ modes observed below 600 $\mathrm{cm}^{-1}$ are usually attributed to the symmetric and antisymmetric bending of oxygen ion in the $\mathrm{M}-\mathrm{O}$ bond at octahedral sites. ${ }^{1,9,15,48}$ And, peaks observed for $>600 \mathrm{~cm}^{-1}$ are assigned to the $A_{1 g}$ mode reflecting the vibrations within tetrahedral sites. ${ }^{1,9, P_{5}, 49}$ From the spectral deconvolution, besides the above-mentioned five Raman-active modes, two additional weakly intense peaks are detected around 115-120 $\mathrm{cm}^{-1}$ and $(213.36,216.48) \mathrm{cm}^{-1}$. The first additional peak positioned at $115-120 \mathrm{~cm}^{-1}$ is due to quantum size effects. ${ }^{9}$ There is an appearance of extra phonon modes because the particle dimensions are significantly smaller than the exciting radiation wavelength, which leads to breakdown of the momentum conservation law. The second additional peaks positioned at $\sim(213.36,216.48) \mathrm{cm}^{-1}$ are ascribed to the $\mathrm{T}_{2 \mathrm{~g}}$ mode of $\alpha-\mathrm{Fe}_{3} \mathrm{O}_{4}$ NPs. ${ }^{50,51} \mathrm{Fe}_{2} \mathrm{O}_{3}$ is the most common impurity or secondary phase that is typically formed during the synthesis of spinel ferrites. It gives sharp signals at 200-240 $\mathrm{cm}^{-1}$ with a high intensity. In the present study, this appears with a low intensity until $x=0.3$ (that could be neglected) and becomes intense only for $x \geq 0.4$. This observation suggests that the CMFO NPs are highly crystalline (free of noncrystalline secondary phase) up to $x(\mathrm{Mn})=0$. For a higher value of $x(\mathrm{Mn}), \geq 0.4$, the secondary phase may become evident. However, it is important to recognize that the secondary phase is not at all detected in XRD.

The $A_{1 g}$ mode is assigned to a shoulder peak positioned around 594-599 $\mathrm{cm}^{-1}$ for each sample (labeled as $A_{1 \mathrm{~g}}(2)$ ). It is remarkable that, with increasing $x(\mathrm{Mn})$, the intensities of $\mathrm{T}_{2 \mathrm{~g}}(1)$ and $\mathrm{A}_{1 \mathrm{~g}}(1)$ decrease, while that of the $\mathrm{A}_{1 \mathrm{~g}}(2)$ peak increases. These observations may be a sign of alteration in cation distribution with $\mathrm{Mn}$ substitution. A reduction in the intensity of the peak due to $\mathrm{FeO}_{4}\left(\mathrm{~A}_{1 \mathrm{~g}}(1)\right)$, and an increase in the intensity of the peak due to $\mathrm{CoO}_{4}\left(\mathrm{~A}_{1 g}(2)\right)$ with the degree of $\mathrm{Mn}$ substitution suggest specifically the redistribution of $\mathrm{Co}^{2+}$ and $\mathrm{Fe}^{3+}$ ions in the tetrahedral and octahedral sites of the spinel lattice. It may be noted that the presence of the $A_{1 g}(2)$ mode is a characteristic feature of cobalt ferrite, irrespective of the microstructure. Furthermore, the $\mathrm{A}_{1 \mathrm{~g}}(2)$ 

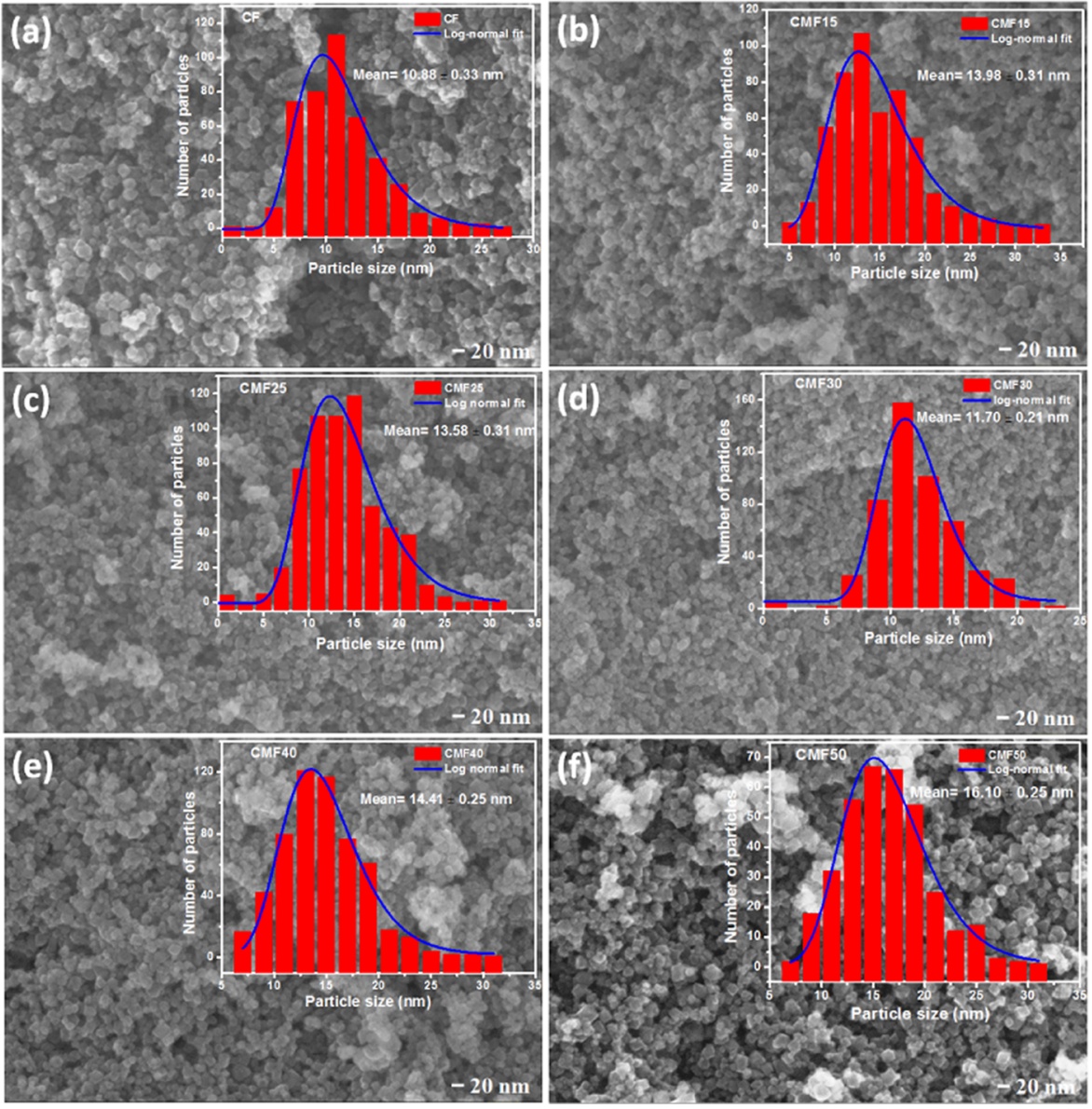

Figure 4. FE-SEM images of (a) CF, (b) CMF15, (c) CMF25, (d) CMF30, (e) CMF40, and (f) CMF50 NPs (the inset shows the size histogram with lognormal fitting curve (solid line)).

mode is attributed to the local distortion in the coordination environment due to inhomogeneous distribution of cations among the $\mathrm{A}$ and $\mathrm{B}$ sites in the mixed spinel structure. ${ }^{52}$ The magnetic measurements indicate the distribution of $\mathrm{Co}, \mathrm{Mn}$, and $\mathrm{Fe}$ in the tetrahedral and octahedral sites. Note that the doublet-like shape of $\mathrm{A}_{1 \mathrm{~g}}$ is well observed up to $x=0.3$, at which point both the peaks become relatively broad with a further increase in $x$. Relative area and height ratio (Table S1) of Raman-active modes of octahedral to tetrahedral sites indicate that the $A_{1 g}(1)$ and $A_{1 g}(2)$ modes are highly affected, suggesting the fact that the tetrahedral as well as octahedral sites are significantly manipulated with the Mn substitution. This fact is mostly ascribed to the collective effect of: (i) the existence of $\mathrm{Mn}^{2+}, \mathrm{Co}^{2+}$, and $\mathrm{Fe}^{3+}$ at the octahedral site and (ii) migration of some of the $\mathrm{Co}^{2+}$ ions from the octahedral to tetrahedral site. This fact can be supported by the magnetic characteristics and refinement data. In addition, the intensity change of the $A_{1 g}(2)$ mode with the $\mathrm{Mn}$ content can be associated with the modification of bond lengths and bond angles (see Table 2), as extracted from the refinement of XRD data. Furthermore, it is reported that the bulk $\mathrm{MnFe}_{2} \mathrm{O}_{4}$ and $\mathrm{CoFe}_{2} \mathrm{O}_{4}$, even if resembling a spinel structure, they do not have a similar cation distribution among the octahedral and tetrahedral sites. ${ }^{53}$ Bulk $\mathrm{MnFe}_{2} \mathrm{O}_{4}$ results in a partially inverted spinel structure with $\mathrm{Mn}(\mathrm{II})$ cations mostly preferring the tetrahedral sites, causing a low inversion degree (0.2, i.e., $20 \%$ of $\mathrm{Mn}$ (II) cations in octahedral sites). On the other hand, $\mathrm{CoFe}_{2} \mathrm{O}_{4}$ has a significantly higher inversion degree (0.8), with
$\mathrm{Co}$ (II) cations preferring the octahedral positions and $\mathrm{Fe}$ (III) cations being shared between the octahedral and tetrahedral sites. A gradual shift of the degree of inversion of spinel lattice at nanoscale can be seen with change in $x$ from 0.0 to 0.5 ; this can be ascribed to the variation in area and intensity of the band associated with the octahedral sites relative to the band associated with the tetrahedral sites. This means that a different distribution of the divalent and trivalent cations between the tetrahedral and octahedral sites occurs even at nanoscale dimensions. When $\mathrm{Mn}$ varies from 0.0 to 0.5 , we observe $A_{1 g}$ splitting, which means the cation migration within both types of sites. A similar behavior is reported in the literature. ${ }^{54-56}$

Note that $\mathrm{T}_{2 \mathrm{~g}}(3)$ and $\mathrm{A}_{1 \mathrm{~g}}(2)$ modes show shifts toward the lower wavenumber with increase of the Mn content compared to CF NPs. The position of $\mathrm{T}_{2 \mathrm{~g}}(3)$ is found to be at 188.48, $168.86,169.99,167.65,167.98$, and $158.30 \mathrm{~cm}^{-1}$ for the $\mathrm{CF}$, CMF15, CMF25, CMF30, CMF40, and CMF50 samples, respectively, which implies that red shifts of 19.62, 18.49, $20.83,20.50$, and $30.18 \mathrm{~cm}^{-1}$ are observed for the CMF15, CMF25, CMF30, CMF40, and CMF50 samples, respectively, compared to the CF sample. Similarly, the $A_{1 g}(2)$ mode is observed at 599.34, 595.50, 595.00, 596.79, 597.95, and 597.33 $\mathrm{cm}^{-1}$ for the CF, CMF15, CMF25, CMF30, CMF40, and CMF50 samples, respectively, which shows red shifts of 3.84 , $4.34,2.55,1.39$, and $2.01 \mathrm{~cm}^{-1}$ for the CMF15, CMF25, CMF30, CMF40, and CMF50 samples, respectively, compared to the CF sample. In the present study, the shift toward the 

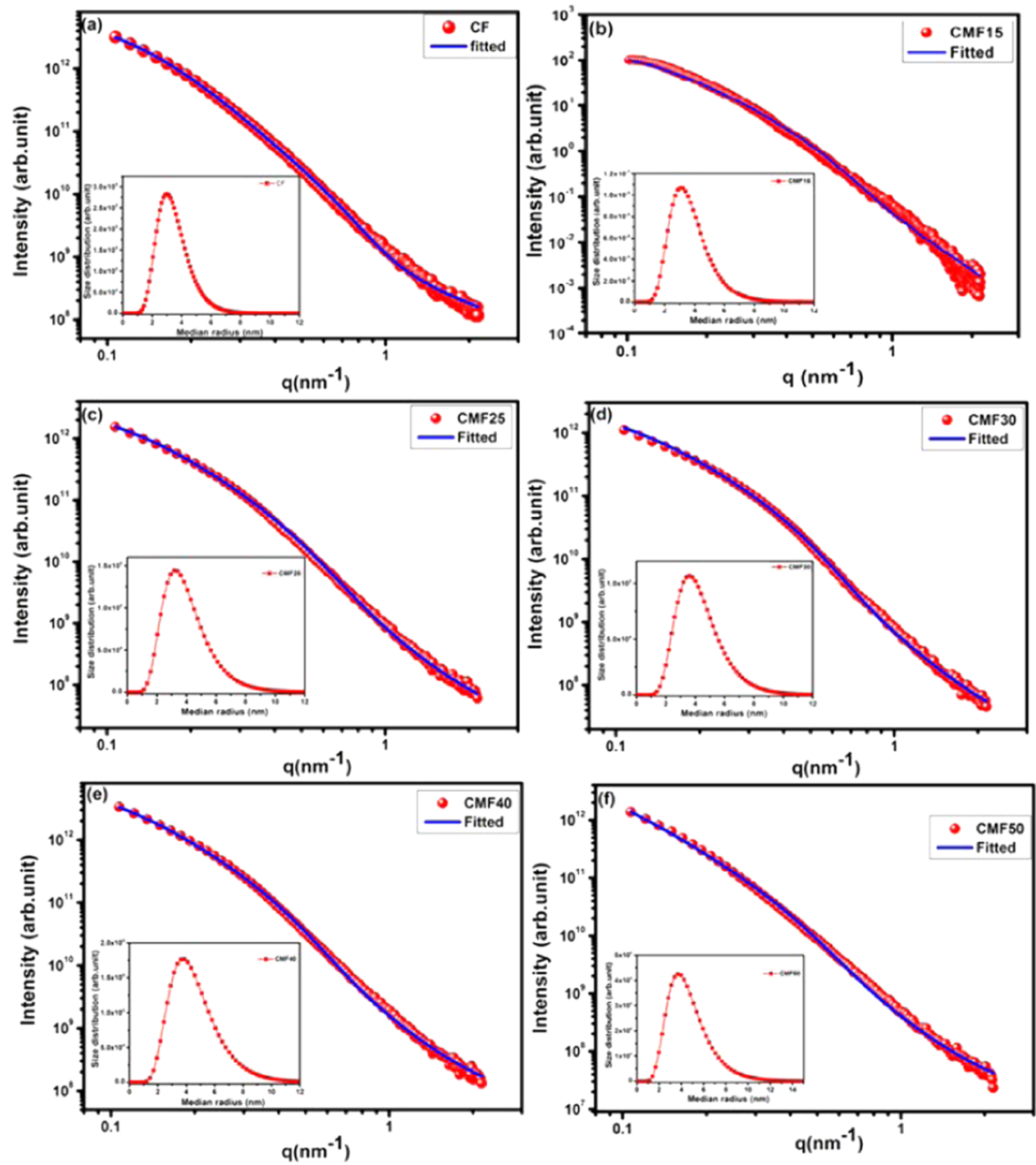

Figure 5. SAXS data of (a) CF, (b) CMF15, (c) CMF25, (d) CMF30, (e) CMF40, and (f) CMF50 samples (the inset shows the size distribution as estimated from SAXS data). The solid line represents fit of the model to the experimental data.

lower wavenumber is attributed to the homogeneous strain developed in the lattice compared to the bulk compound, ${ }^{57}$ confinement effects, and inhomogeneous strain due to the distribution in particle size. ${ }^{58}$ The substitution of larger-ionicradius $\mathrm{Mn}$ (II) ions (0.83 $\AA$ ) forces the lattice to expand, which can develop strain in the lattice. The development of strain in the lattice is also seen in the XRD spectrum shown in Figure 2 as a shift of the diffraction peaks and expansion of lattice constant given in Table 1. A similar behavior of red shift due to the expansion of lattice parameter is observed for indiumsubstituted CFO NPs," ${ }^{59} 60$ which are prepared with different concentrations of oleic acid, zinc ferrite, ${ }^{61}$ and $\mathrm{NiFe}_{2} \mathrm{O}_{4} \mathrm{NPs}^{58}$ However, Chandramohan et al. ${ }^{47}$ accounted that the decrease in grain size results in a red shift with broadening of peak. In nanocrystals, due to lack of long-range order, both the phonons, one having $q=0$ and the other $q>0$, take part in the scattering process, which can show the broadening and shift of peak position in the Raman spectra. Furthermore, Singh et al. ${ }^{60}$ reported that the shift toward lower wavenumber is ascribed to the crystalline disorder and the presence of grain boundaries, which are large in small nanomaterials. Furthermore, the bandwidth of the Raman signal shows broadening for small nanomaterials $(\sim 20 \mathrm{~nm})$, which also supports the crystalline disorder. The Raman shift toward a lower wavenumber and line broadening are observed in polycrystalline materials and are attributed to the confinement of optical phonons in small crystalline particles. On the other hand, the $\mathrm{T}_{2 \mathrm{~g}}(2)$ mode is positioned at 454.37, 459.14, 457.72, 457.62, 460.00 , and $460.77 \mathrm{~cm}^{-1}$ for the CF, CMF15, CMF25, CMF30, CMF40, and CMF50 samples, respectively, which shows blue shifts of $4.77,3.35,3.25,5.63$, and $6.40 \mathrm{~cm}^{-1}$ for the CMF15, CMF25, CMF30, CMF40 and CMF50 samples, respectively, compared to the $\mathrm{CF}$ sample. It is interesting to note that the red shift of the $\mathrm{T}_{2 \mathrm{~g}}(3)$ mode and the blue shift of the $\mathrm{T}_{2 \mathrm{~g}}(2)$ mode increase linearly with the Mn content. The $\mathrm{E}_{\mathrm{g}}$ and $\mathrm{A}_{1 \mathrm{~g}}(1)$ modes of the CMF25 and CMF30 samples exhibit a blue shift (see Table S1), which is attributed to the sizedependent compressive stress in the NPs. ${ }^{62}$

Morphology and Size Distribution Characteristics. Field Emission Scanning Electron Microscopy (FE-SEM). High-magnification FE-SEM images of the CMFO NPs are shown in Figure 4.

The size distribution is also shown in the inset. The parameters obtained from the analyses are listed in Table S2. The images confirm the presence of nanosize particles, which are uniformly distributed. The size distribution data of NPs are fitted with a lognormal function. The lognormal distribution of the particle size is observed to be symmetrical for all of the samples. The estimated size values are $\sim 10.86,13.96,13.58$, $11.70,14.41$, and $16.10 \mathrm{~nm}$ for the CF, CMF15, CMF25, CMF30, CMF40, and CMF50 samples, respectively. Furthermore, it is observed that the polydispersity index $(\sigma)$ of 
CMFO NPs slightly decreases from $\sim 0.33$ to 0.21 when $x$ varies from 0.00 to 0.30 , and after that, the $\sigma$ value again slightly increases up to 0.25 . It implies that the $\mathrm{Mn}$ (II) substitution controls the polydispersity index (NP size distribution). The smaller value of polydispersity index $(\sigma \leq$ 0.33) of particle distribution indicates that the Mn-substituted NPs are well confined to a limited diameter range.

Small-Angle X-ray Scattering (SAXS). The CMFO samples were probed by the SAXS technique to further probe the details of particle morphology and size. As shown in Figure 5, the scattering profiles indicate a more or less similar tendency or behavior for all of the samples. The mesoscopic density fluctuation in each MNPs is represented by scattered intensity $I(q)$, where $q$ is the scattering vector. ${ }^{63}$ In the present case, the scattering profiles of all of the samples have been analyzed based on the polydisperse spherical particle model under monodispersed approximation. ${ }^{64}$ The scattering intensity $I(q)$ can be written as

$$
I(q)=C \int_{0}^{\infty} P(q, R) S(q, R) R^{6} D(R) \mathrm{d} R
$$

Here, $C$ is the scale factor, and $P(q, R)$ and $S(q, R)$ signify the form factor and interparticle structure factor, respectively. Assuming the spherical shape of particles with radius $R$, the form factor $P(q, R)$ is expressed as ${ }^{64}$

$$
P(q, R)=\left[\frac{3 \sin (q R)-q R \cos (q R)}{(q R)^{3}}\right]^{2}
$$

$D(R)$ represents the size distribution and is assumed to be normalized lognormal distribution. ${ }^{65}$

$$
D(R)=\frac{N}{\sqrt{2 \pi \sigma^{2}} R} \exp \left[-\left[\ln \left(R / R_{0}\right)\right]^{2} / 2 \sigma^{2}\right]
$$

where $N$ is the normalization factor, and $R_{0}$ and $\sigma$ represent the median radius and polydispersity index, respectively. In the whole accessible " $q$ " range of SAXS profiles, the power law dependence of $I(q)$ on $q$, i.e., the linear relation between double-logarithmic scale and the noninteger exponent of power law, indicates a fractal-like structure factor for each sample, irrespective of assembling of NPs and aggregation. Thus, the fractal structure factor ${ }^{60,67}$ is given as

$$
S\left(q, r_{0}\right)=1+\frac{D}{r_{0}^{D}} \int_{0}^{\infty} r^{D-3} h(r, \xi) \frac{\sin (q r)}{q r} r^{2} \mathrm{~d} r
$$

with the cutoff function as

$$
h_{\text {exp }}(r, \xi)=\exp \left[-\left(\frac{r}{\xi}\right)\right]
$$

where $D$ is the fractal dimension $(1<D<3), r_{\mathrm{o}}$ is the radius of monomer, $h(r, \xi)$ is the cutoff function, and $x$ is the cutoff length for fractal correlation. The structural parameters obtained from SAXS analysis are listed in Table 4. The inset of Figure 6 shows the size distribution profiles of basic NPs, which are almost corroborating with the same information obtained from XRD. It is notable that, with an increase of the $\mathrm{Mn}$ content, the median radius $(R)$ value also increases. In addition, the scattering intensity increases slightly toward the low- $q$ region, which implies that the agglomeration of particles increases slightly as is also noted in FE-SEM. It is observed that the characteristic dimension of the individual scatter also
Table 4. Structural Parameters Obtained from SAXS

\begin{tabular}{lcccccc} 
& \multicolumn{6}{c}{ samples } \\
\cline { 2 - 7 } parameters & CF & CMF15 & CMF25 & CMF30 & CMF40 & CMF50 \\
$\begin{array}{c}\text { median radius } \\
(R, \mathrm{~nm})\end{array}$ & 3.29 & 3.50 & 3.74 & 4.08 & 4.32 & 4.34 \\
$\begin{array}{c}\text { polydispersity } \\
\text { index }(\sigma, \mathrm{nm})\end{array}$ & 0.31 & 0.35 & 0.38 & 0.35 & 0.37 & 0.39 \\
$\begin{array}{c}\text { radius of } \\
\text { monomer }\left(r_{\mathrm{o}},\right.\end{array}$ & 2.84 & 3.64 & 5.00 & 5.49 & 5.92 & 6.00 \\
$\begin{array}{c}\mathrm{nm}) \\
\text { size of aggregate } \\
\left(x_{\mathrm{i}}, \mathrm{nm}\right)\end{array}$ & 8.00 & 8.25 & 8.54 & 9.00 & 9.54 & 15.97 \\
$\begin{array}{c}\text { fractal } \\
\text { dimension }\end{array}$ & 2.91 & 2.50 & 2.50 & 2.50 & 2.50 & 2.50 \\
$(D)$
\end{tabular}
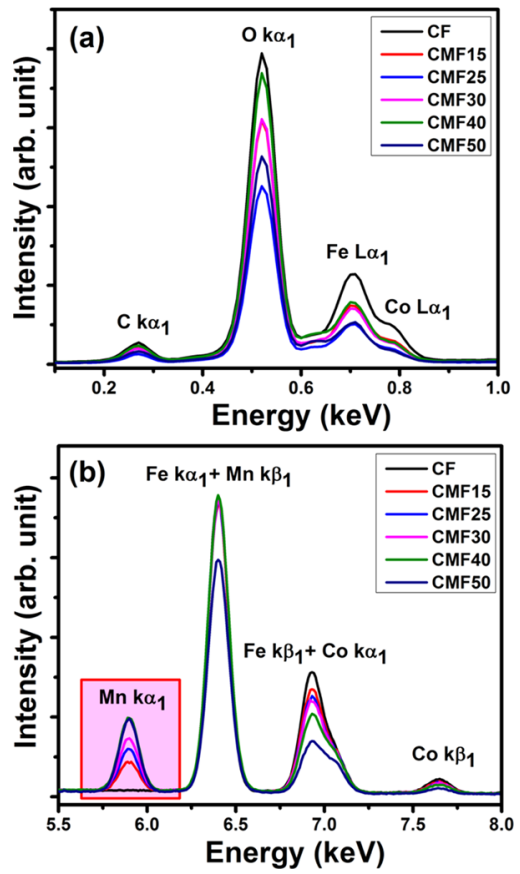

Figure 6. EDS spectra of CMFO nanoparticles in the range of (a) 0$1.0 \mathrm{keV}$ and (b) $5.5-8.0 \mathrm{keV}$, where $\mathrm{Mn}$ the $\left(\mathrm{k} \alpha_{1}\right)$ peak region is marked. An evolution of intensity of the Mn peak confirms the Mn incorporation into CFO.

increases with the Mn content along with the increase in fractal aggregate $\left(x_{\mathrm{i}}\right)$, as observed from the FE-SEM images. Thus, it should also be pointed out that the concentration of $\mathrm{Mn}$ effectively affects the NP size distribution and agglomeration. Thus, using the present approach, one can tune the NPs size according to the targeted application. However, the slight dissimilarities in the trend of size distribution and polydispersity index can be attributed to the fact that the applied scattering tools are believed to give the overall structural information about the system, while FE-SEM provides the selective information based on the region of interest.

Chemical Composition. Energy-Dispersive X-ray Spectrometry (EDS). The EDS measurements indicate that the pristine CMFO nanomaterials are stoichiometric and homogeneous with a uniform distribution. The characteristic peaks of $\mathrm{Co}, \mathrm{Fe}, \mathrm{Mn}$, and $\mathrm{O}$ are evident in the EDS of CMFO shown in Figure S2. X-ray energy is a characteristic of generating atom and, therefore, detection of X-rays emitted provides the signature of atoms present. ${ }^{68}$ Therefore, EDS measurements can be used to qualitatively discuss the chemical quality of the 

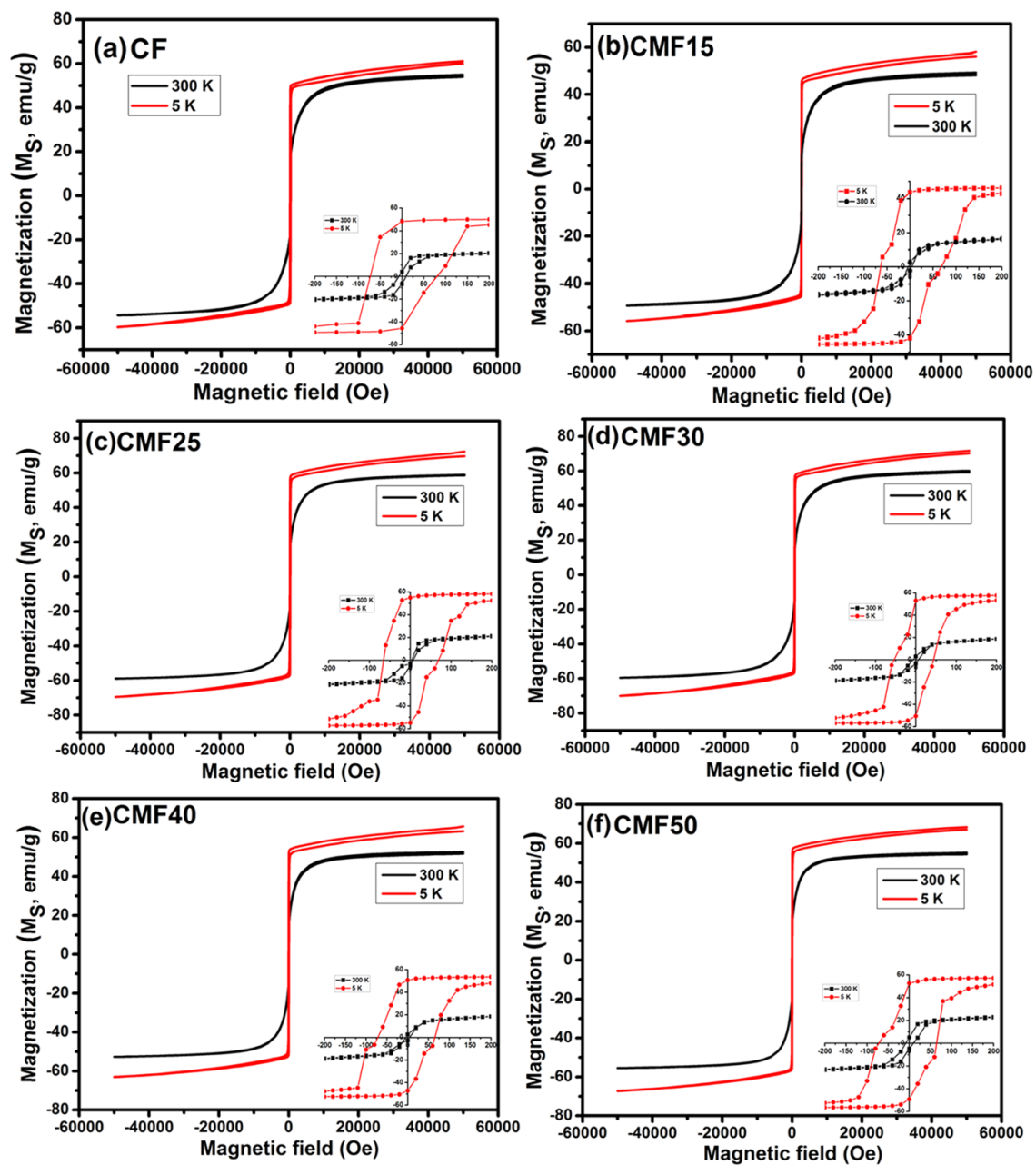

Figure 7. (M)-H hysteresis loops for (a) CF, (b) CMF15, (c) CMF25, (d) CMF30, (e) CMF40, and (f) CMF50 NPs measured under an applied field $\pm 50 \mathrm{kOe}$.

\section{Table 5. Magnetic Parameters}

\begin{tabular}{|c|c|c|c|c|c|c|c|c|}
\hline \multirow{2}{*}{$\frac{\text { parameters }}{\text { samples }}$} & \multicolumn{2}{|c|}{$\begin{array}{c}\text { maximum saturation } \\
\text { magnetization }\left(M_{S}, \text { emu/gm }\right) \text { at }\end{array}$} & \multicolumn{2}{|c|}{$\begin{array}{c}\text { remanent magnetization }\left(M_{\mathrm{r}},\right. \\
\mathrm{emu} / \mathrm{g}) \text { at }\end{array}$} & \multicolumn{2}{|c|}{ coercivity $\left(H_{\mathrm{C}}, \mathrm{Oe}\right)$ at } & \multicolumn{2}{|c|}{ squareness ratio $\left(M_{\mathrm{r}} / M_{\mathrm{S}}\right)$ at } \\
\hline & $300 \mathrm{~K}$ & $5 \mathrm{~K}$ & $300 \mathrm{~K}$ & $5 \mathrm{~K}$ & $300 \mathrm{~K}$ & $5 \mathrm{~K}$ & $300 \mathrm{~K}$ & $5 \mathrm{~K}$ \\
\hline CF & 54.65 & 60.43 & 5.41 & 46.92 & 8.19 & 76.70 & 0.099 & 0.776 \\
\hline CMF-15 & 49.23 & 56.92 & 2.37 & 42.72 & 3.87 & 65.66 & 0.049 & 0.75 \\
\hline CMF-25 & 58.90 & 70.82 & 3.64 & 54.81 & 5.05 & 67.77 & 0.062 & 0.774 \\
\hline CMF-30 & 59.86 & 70.86 & 3.07 & 51.82 & 6.73 & 48.68 & 0.051 & 0.731 \\
\hline CMF-40 & 52.67 & 58.09 & 2.59 & 48.92 & 4.78 & 68.55 & 0.049 & 0.842 \\
\hline CMF-50 & 55.32 & 67.8 & 5.56 & 51.04 & 9.05 & 68.51 & 0.100 & 0.752 \\
\hline
\end{tabular}

CMFO samples. The observed lines in the EDS spectra are identified, and they belong to Co $\left(\mathrm{L} \alpha_{1}, \mathrm{k} \alpha_{1}, \mathrm{k} \beta_{1}\right)$, Fe ( $\mathrm{L} \alpha_{1}, \mathrm{k} \alpha_{1}$, $\left.\mathrm{k} \beta_{1}\right), \mathrm{Mn}\left(\mathrm{k} \alpha_{1}, \mathrm{k} \beta_{1}\right)$, and $\mathrm{O} \mathrm{k} \alpha_{1}$ at their respective energy positions. This confirms that the X-rays are only due to $\mathrm{Co}, \mathrm{Fe}$, $\mathrm{Mn}$, and $\mathrm{O}$ present in the CMFO samples. Thus, it is evident from the data that pristine CMFO NPs are chemically homogeneous without any impurities and/or contaminating elements from reagents. Such chemical homogeneity coupled with narrow size distribution of the particles is quite important for utilizing CFO NPs for biomedical and health science applications. An effective incorporation of $\mathrm{Mn}$ into the $\mathrm{CFO}$ lattice can be seen from the peak region of Mn shown in Figure $6 \mathrm{~b}$, where the evolution of the $\mathrm{Mn} \mathrm{k} \alpha_{1}$ peak is seen only in $\mathrm{Mn}$ substituted samples. As we have used carbon tape while making samples for EDS measurements, X-ray lines from the carbon tape $\left(\mathrm{C} \mathrm{k} \alpha_{1}\right)$ can also be seen (Figure 6a). The presence of only peaks of $\mathrm{Co}, \mathrm{Fe}, \mathrm{Mn}$, and $\mathrm{O}$ and the absence of any other peaks confirm the purity and chemical quality of the synthesized CMFO nanomaterials. Furthermore, the increase of peak intensity is attributed to the increase of $\mathrm{Mn}$ incorporation into CFO, which is as expected.

Magnetic Properties. Magnetic data of CMFO samples are presented in Figure 7, while Table 5 covers the magnetic parameters, namely, maximum saturation magnetization $\left(M_{\mathrm{S}}\right)$, remnant magnetization $\left(M_{\mathrm{r}}\right)$, coercivity $\left(H_{\mathrm{C}}\right)$, and squareness ratio $\left(M_{\mathrm{r}} / M_{\mathrm{S}}\right)$. At room temperature $(300 \mathrm{~K})$, the $\mathrm{M}-(\mathrm{H})$ curves of CMFO reveal the lower value of coercivity $(<10 \mathrm{Oe})$ with a negligible $M_{\mathrm{r}}$ value, indicating that all of the CMFO NPs 

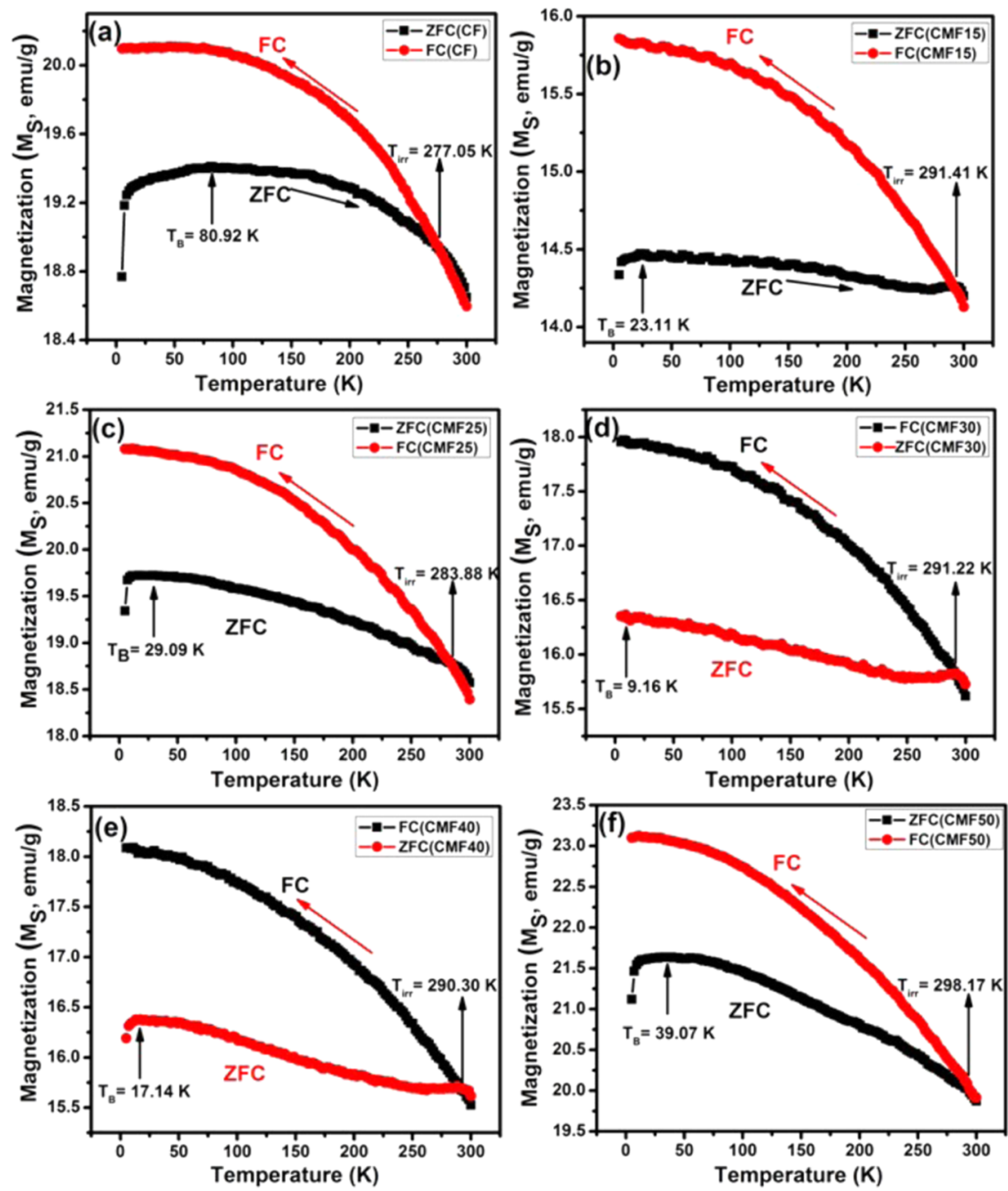

Figure 8. ZFC-FC curves for (a) CF, (b) CMF15, (c) CMF25, (d) CMF30, (e) CMF40, and (f) CMF50 magnetic nanoparticles measured under the applied field $100 \mathrm{Oe}$ in the temperature of 5-300 K. The blocking temperature $\left(T_{\mathrm{B}}\right)$ and irreversibility temperature $\left(T_{\text {irr }}\right)$ values are highlighted by arrows.

have superparamagnetic behavior at $300 \mathrm{~K}$. Note that, for the $\mathrm{CF}$ sample, the $M_{\mathrm{S}}$ value is low $\left(54.65 \mathrm{emu} / \mathrm{g}\right.$ or $2.30 \mu_{\mathrm{B}} / \mathrm{FU}$ at $300 \mathrm{~K})$ compared to the theoretical value of an ideal inverse CFO structure $\left(\sim 3 \mu_{\mathrm{B}} / \mathrm{FU}\right)$ as well as the bulk counterpart ( 80 $\mathrm{emu} / \mathrm{g}$ ).Here, a decrease in the $M_{\mathrm{S}}$ value for CF may be attributed to (i) the surface disorder or spin canting at the NP surface. ${ }^{69}$ Note that the number of atoms on the surface is maximum for NPs causing the reduction of magnetization. The effective reduction in magnetization of NPs is, therefore, due to the presence of randomized surface spins and the nonstoichiometric cation distribution $\left(\mathrm{Fe}^{+3}, \mathrm{Co}^{+2}\right)$ among the octahedral and tetrahedral sites compared to the ideal spinel structure $\left[\mathrm{Fe}^{+3}\right]\left\{\mathrm{Co}^{+2} \mathrm{Fe}^{+3}\right\} \mathrm{O}^{-2}$ as predicted by XRD refinement and Raman spectroscopy. Thus, to provide a deeper and thorough understanding of magnetic properties, and specifically the superparamagnetism at $300 \mathrm{~K}, \mathrm{M}-(\mathrm{H})$ measurements were performed at $5 \mathrm{~K}$ (Figure 7 ), where the contribution of spin wave thermal fluctuations is negligible. In the present study (Table 5), magnetization $\left(M_{\mathrm{S}}\right)$ and remnant magnetization $\left(M_{\mathrm{r}}\right)$ are observed to enhance with $\mathrm{Mn}^{2+}$ substitution up to $x=0.3$ and then decline. The observed behavior of the results match well with the reported work on manganesesubstituted cobalt ferrite. ${ }^{70-72}$ The observed maximum magnetization (for $\mathrm{Mn}=0.3$ ) is attributed to the replacement of $\mathrm{Co}^{2+}\left(\mathrm{d}^{7}\right)\left(3 \mu_{\mathrm{B}}\right)$ by $\mathrm{Mn}^{2+}\left(\mathrm{d}^{5}\right)\left(5 \mu_{\mathrm{B}}\right)$. However, if the manganese is substituted as $\mathrm{Mn}^{2+}\left(5 \mu_{\mathrm{B}}\right)$ and/or $\mathrm{Mn}^{3+}\left(4 \mu_{\mathrm{B}}\right)$ at higher $\mathrm{Mn}(\geq 0.4)$ concentrations, then the magnetization is expected to diminish due to (i) the conversion of equivalent amounts of $\mathrm{Fe}^{3+}\left(5 \mu_{\mathrm{B}}\right)$ to $\mathrm{Fe}^{2+}\left(4 \mu_{\mathrm{B}}\right)$ and (ii) the simultaneous shift of some of the Co from the octahedral to tetrahedral site. This fact can be understood as: increasing the valence of $\mathrm{Mn}$ ions from $2+, 3+$, to 4+ would lower the overall magnetization, and overoxidation of the $\mathrm{Mn}$ ions would increase the chances of $\mathrm{Mn}$ ions occupying octahedral sites. ${ }^{73}$ This reduced magnetization may be good for magnetomechanical stress and torque sensors. ${ }^{74,75}$ In addition, for the CMF15 sample, the $M_{\mathrm{S}}$ value does not follow the trend as the secondary phase is detected. Furthermore, it is known for the ferrite system that the magnetic properties are strongly influenced by the cation distribution among the tetrahedral and octahedral sites, in addition to the exchange interactions between the magnetic ions occupying the $\mathrm{B}$ and $\mathrm{A}$ sites. ${ }^{76}$ The net magnetic moment is the difference in moments of $\mathrm{B}$ and $\mathrm{A}$ sublattices, i.e., $M=M_{\mathrm{B}}-M_{\mathrm{A}}$. Essentially, magnetic properties of ferrite depend on the chemical composition, which determines the intrinsic properties, along with the micro- 
Table 6. Blocking Temperature $\left(T_{\mathrm{B}}\right)$, Irreversibility Temperature $\left(T_{\mathrm{irr}}\right)$, Effective Anisotropy Constant $\left(K_{\text {eff }}\right)$, and Exchange Bias Field $\left(H_{\mathrm{ex}}\right)$ Obtained from the Magnetic Data

\begin{tabular}{|c|c|c|c|c|c|c|c|c|c|}
\hline \multirow[b]{2}{*}{ sample } & \multirow[b]{2}{*}{$T_{\mathrm{B}}(\mathrm{K})$} & \multirow[b]{2}{*}{$T_{\text {irr }}(\mathrm{K})$} & \multirow[b]{2}{*}{$K_{\text {eff }}\left(\mathrm{erg} / \mathrm{cm}^{3}\right)$} & \multicolumn{2}{|c|}{$H_{\text {right }}(\mathrm{Oe})$ at } & \multicolumn{2}{|c|}{$H_{\text {left }}(\mathrm{Oe})$ at } & \multicolumn{2}{|c|}{$H_{\mathrm{ex}}(\mathrm{Oe})$ at } \\
\hline & & & & $300 \mathrm{~K}$ & $5 \mathrm{~K}$ & $300 \mathrm{~K}$ & $5 \mathrm{~K}$ & $300 \mathrm{~K}$ & $5 \mathrm{~K}$ \\
\hline CF & 80.91 & 277.1 & $1.03 \times 10^{6}$ & 9.33 & 80.93 & -7.06 & -72.47 & 1.14 & 4.23 \\
\hline CMF-15 & 23.11 & 291.4 & $2.77 \times 10^{5}$ & 3.80 & 67.55 & -3.94 & -63.77 & -0.07 & 1.89 \\
\hline CMF-25 & 29.09 & 283.9 & $1.64 \times 10^{5}$ & 6.77 & 69.36 & -3.33 & -66.13 & 1.72 & 1.62 \\
\hline CMF-30 & 09.16 & 291.2 & $3.38 \times 10^{4}$ & 6.49 & 43.78 & -6.97 & -53.59 & -0.24 & -4.91 \\
\hline CMF-40 & 17.13 & 290.3 & $7.16 \times 10^{4}$ & 4.72 & 65.25 & -4.78 & -71.85 & -0.03 & -3.30 \\
\hline CMF-50 & 39.07 & 298.2 & $9.93 \times 10^{4}$ & 9.92 & 64.924 & -8.17 & -72.09 & 0.88 & -3.58 \\
\hline
\end{tabular}

structure. Thus, a change in magnetization with $\mathrm{Mn}$ substitution in CFO can be attributed to the variation of magnetic moment contribution from the tetrahedral and octahedral sites and also to the decreased contribution from the magnetocrystalline anisotropy of cobalt with manganese substitution. This is supported by the cation distribution obtained from the XRD data and Raman spectroscopy.

More importantly, parameters such as particle size, cation distribution, exchange couple interaction, and surface area-tovolume ratio drive the magnetic properties. Hence, the $M_{\mathrm{S}} /$ $D_{\text {XRD }}$ values should be compared while making a direct comparison between the magnetic properties of nanostructured granules. While evaluating the performance of nanomaterials for biotechnological applications, in particular, the relationship between the $M_{\mathrm{S}}$ value (near room temperature) and the particle size is of importance. ${ }^{77,78}$ In this connection, the $M_{\mathrm{S}} / D_{\mathrm{XRD}}$ value as a function of $\mathrm{x}$ (Mn content) was determined at $300 \mathrm{~K}$ and is plotted in Figure S2. The results follow similar trends, with CMF30 $\left(\mathrm{Co}_{0.7} \mathrm{Mn}_{0.3} \mathrm{Fe}_{2} \mathrm{O}_{4}\right)$ presenting the highest $M_{\mathrm{S}} / D_{\text {XRD }}$ values. We can find similar results from Raman analysis for relative width, area, and intensity ratio of the tetrahedral to octahedral site. More importantly, the $\mathrm{Co}_{0.7} \mathrm{Mn}_{0.3} \mathrm{Fe}_{2} \mathrm{O}_{4}$ nanomaterial shows the highest $M_{\mathrm{S}} / D_{\mathrm{XRD}}$ values (Figure S3) and when normalizing the $M_{\mathrm{S}}$ values at $5 \mathrm{~K}$ to $D_{\mathrm{XRD}}$, we achieve a similar behavior to that observed at $300 \mathrm{~K}$.

Furthermore, as mentioned above, we can confirm the superparamagnetic behavior for all of the CMFO NPs because $\mathrm{M}-(\mathrm{H})$ curves (at $300 \mathrm{~K}$ ) of the CMFO samples reveal the lower value $(<10 \mathrm{Oe})$ of coercivity with a negligible $M_{\mathrm{r}}$. In addition, a monotonic increase in coercivity $\left(H_{\mathrm{C}}\right)$ is observed at $5 \mathrm{~K}$ compared to the coercivity observed at $300 \mathrm{~K}$ for all CMFO NPs (see Table 5). The reason for the increase in coercivity with a decrease in temperature can be understood by considering the effects of thermal fluctuations of the blocked magnetic moment across the anisotropy barrier. It is to be noted that when we are dealing with NPs at low temperatures, the anisotropy may be a strong function of temperature. ${ }^{79}$ Thus, in the case of MNPs, other factors, apart from the enhancement of anisotropy, like the structural properties that are intrinsic to NPs, including volume distribution, randomness of anisotropy axes, and interparticle interactions, may also influence the thermal dependence of coercivity. ${ }^{80}$ Moreover, the squareness ratio $\left(R=M_{\mathrm{r}} / M_{\mathrm{S}}\right)$ was found in the range of $0.73-0.84$ (at $5 \mathrm{~K}$ ); the high $R$ values suggest the tendency toward cubic anisotropy. Furthermore, the $R$ value at $5 \mathrm{~K}$ suggests the dominance of exchange coupling $(0.5<R<1)$ and magnetostatic interactions $(R<0.5)$ at $300 \mathrm{~K}$ among the MNPs.

Moreover, the $\mathrm{ZFC}-\mathrm{FC}$ curves measured in the temperature range of $5-300 \mathrm{~K}$ at an applied field of $100 \mathrm{Oe}$ are shown in Figure 8. The irreversibility between the ZFC and FC curves starts well below $300 \mathrm{~K}$, which indicates that the overcoming of superparamagnetic limit in all of the samples is below $300 \mathrm{~K}$. The bifurcation between the values of FC and ZFC magnetization increases with decreasing temperature. This behavior suggests the high anisotropic behavior of MNPs. It is seen from the $\mathrm{ZFC}-\mathrm{FC}$ curve that, as the temperature increases (ZFC measurements), $\mathrm{M}_{\mathrm{ZFC}}$ increases first and then attains the maximum value at a specific temperature called blocking temperature $\left(T_{\mathrm{B}}\right)$. In the present study, $T_{\mathrm{B}}$ is found to be $80.92,23.11,29.09,9.16,17.14$, and $39.07 \mathrm{~K}$ for $\mathrm{CF}$, CMF15, CMF25, CMF30, CMF40, and CMF50, respectively. Above $T_{\mathrm{B}}$ (in the unblocked region), $\mathrm{M}_{\mathrm{ZFC}}$ monotonically decreases with increasing temperature. Below $T_{B}$, the magnetic anisotropy energy is larger than the thermal energy and therefore blocks the magnetic moments orienting in the direction of a small magnetic field. Note that the $T_{B}$ values of Mn-substituted CFO NPs are found to be decreased compared to those of the pure $\mathrm{CoFe}_{2} \mathrm{O}_{4} \mathrm{NPs}$, and a considerably (Figure 8 and Table 6) lower value of $T_{\mathrm{B}}$ is observed for CMF30 NPs $\left(T_{\mathrm{B}}=9.16 \mathrm{~K}\right)$. This may be related to the lowering of intersublattice exchange coupling between $\mathrm{A}$ and $\mathrm{B}$ sublattices. As reported for bulk ferrites, the exchange integral $\mathrm{J}^{\mathrm{A}} \mathrm{Fe}^{3+}-{ }^{\mathrm{B}} \mathrm{Co}^{2+}$ between the $\mathrm{Fe}^{3+}$ ion in the "A" lattice and $\mathrm{Fe}^{3+}$ in the "B" lattice is larger than $\mathrm{J}^{\mathrm{A}} \mathrm{Fe}^{3+}-{ }^{\mathrm{B}} \mathrm{Mn}^{2+}$ between the $\mathrm{Fe}^{3+}$ ion in the A lattice and $\mathrm{Mn}^{2+}$ in the B lattice. ${ }^{81}$ In addition, when the measurement temperature of magnetization is less than $T_{\mathrm{B}}$, the magnetic grains showed the ferri/ ferromagnetic state. Therefore, in this context, a finite value of coercivity is observed in the range of $48-76$ Oe at $5 \mathrm{~K}$ for CMFO NPs. Furthermore, the width of peak in the ZFC curve is associated with particle size distribution. ${ }^{82}$ Generally, nanoscale particles show superparamagnetic behavior and larger particles show ferri/ferromagnetic behavior. For an ensemble of MNPs with easy axis randomly distributed over the entire space and with a certain size distribution, the total anisotropy energy barrier is distributed over a certain range. Therefore, since the blocking temperature is measured on the entire nanoparticles ensemble, it has to be considered as a mean value. ${ }^{83-86}$ Therefore, the relatively lower blocking temperature observed for $x=0.3$ may be related to the superparamagnetic nature of manganese ferrite.

Now we turn our attention to $T_{\text {irr }}$, which is found to be 277.1, 291.4, 283.9, 291.2, 290.3, and 298.2 K for the CF, CMF15, CMF25, CMF30, CMF40, and CMF50 samples, respectively. The ZFC and FC curves split from each other (Figure 8 ) and, in most of the cases, $T_{\text {irr }}$ corresponds to the blocking temperature of the largest NPs. The splitting between the ZFC and FC magnetization curves is due to: (a) the existence and distribution of energy barriers of magnetic anisotropy and (b) the slow relaxation of MNPs below $T_{B}$. 
Here, the splitting of ZFC and FC magnetization curves occurs at a higher temperature than the blocking temperature in the ZFC curve, which may be due to the size distribution of CMFO NPs. It can be clearly seen from Figure 8 that the $M_{\mathrm{FC}}$ monotonically increases with decreasing temperature and then attains saturation below a certain temperature. For the CF sample, $M_{\mathrm{FC}}$ shows temperature-independent behavior around $74.85 \mathrm{~K}$. This indicates that, in the low-temperature region, the dipolar interaction is prevailing and thus excludes the presence of long-range order or paramagnetic behavior. ${ }^{87}$ This temperature-dependent $\mathrm{ZFC}$ and FC magnetization and the splitting of ZFC and FC magnetizations are the characteristic features of superparamagnetism. Furthermore, for $\mathrm{ZFC} / \mathrm{FC}$ measurements, the total effective magnetic anisotropy constant $\left(K_{\text {eff }}\right)$ value can be deduced from the Stoner-Wohlfarth expression ${ }^{88}$

$$
K_{\text {eff }} V=25 k_{\mathrm{B}} T_{\mathrm{B}}
$$

where $K_{\text {eff }}$ is the effective anisotropy constant, " $V$ " is the volume of particles, $k_{\mathrm{B}}$ is the Boltzmann constant, and $T_{\mathrm{B}}$ is the blocking temperature. $K_{\text {eff }}$ contains all of the different contributions to the effective anisotropy given by magnetocrystalline, shape, surface, and stress magnetic anisotropies. Moreover, a further contribution to the effective magnetic anisotropy can be given by the presence of dipolar and/or exchange interactions among the particles. ${ }^{88,89}$ If one considers the particle mean size " $d$ ", as determined by XRD analysis, a first rough determination of $K_{\text {eff }}$ is possible. The $K_{\text {eff }}$ is found to be $1.03 \times 10^{6} \mathrm{erg} / \mathrm{cm}^{3}$ for CF NPs. This value is lower than the reported value $\left(1.8 \times 10^{6} \mathrm{erg} / \mathrm{cm}^{3}\right)$ for the bulk CFO. This value decreases with increasing Mn content in CMFO samples. It is well documented in the literature that the surface component $\left(K_{\mathrm{S}}\right)$ plays a key role in regulating the magnetic anisotropy of magnetic particles at nanoscale. Usually, magnetic anisotropy decreases with increasing particle size due to increasing $K_{\mathrm{S}}$. Thus, the size and composition of NPs primarily control $K_{\text {eff. }}$ The calculated $K_{\text {eff }}$ values are tabulated in Table 6, together with the parameters extracted from ZFC$\mathrm{FC}$ and $\mathrm{M}-\mathrm{H}$ hysteresis loop measurements at 5 and $300 \mathrm{~K}$. In addition, the presence of the $\mathrm{M}-\mathrm{H}$ loop shifting along the field axis (higher for smaller particles) is also checked for each composition at 300 and $5 \mathrm{~K}$. The shift of loop, usually quantified as the exchange bias field $\left(H_{\mathrm{ex}}=-\left(H_{\text {right }}+H_{\text {left }}\right) / 2\right)$, was already observed in ferromagnetic NPs and nanosized ferrites. Table 6 shows that the $H_{\mathrm{ex}}$ values are negligible, which confirms the absence of oxide layer and exchange coupled with a ferrimagnetically ordered core.

\section{SUMMARY AND CONCLUSIONS}

We can produce the CMFO MNPs with a simple, economic, and eco-friendly one-pot hydrothermal chemical route at a relatively lower temperature $\left(130{ }^{\circ} \mathrm{C}\right)$, where particle size, inversion degree, and saturation magnetization are tailored. With $\mathrm{Mn}(\mathrm{II})$ substitution, one can control the nanoparticle dimensions precisely in the range of $8-14 \mathrm{~nm}$. The saturation magnetization $\left(M_{S}\right)$ value is observed to increase from 60.43 to $70.86 \mathrm{emu} / \mathrm{g}$ (up to $x(\mathrm{Mn})=0.3$ ), with the maximum value of $M_{\mathrm{S}}$ (70.86 emu/g) observed for $\mathrm{Co}_{0.7} \mathrm{Mn}_{0.3} \mathrm{Fe}_{2} \mathrm{O}_{4} \mathrm{NPs}$ due to the substitution of $\mathrm{Co}^{2+}\left(\mathrm{d}^{7}\right)\left(3 \mu_{\mathrm{B}}\right)$ by $\mathrm{Mn}^{2+}\left(\mathrm{d}^{5}\right)\left(5 \mu_{\mathrm{B}}\right)$. The $M_{\mathrm{S}}$ value decreases (both at 300 and $5 \mathrm{~K}$ ) with further increasing $\mathrm{Mn}$ content. Interestingly, the relative width, area, and intensity ratio of the tetrahedral to octahedral site, from Raman analysis, exhibited a similar character, which demonstrates the cation migration between $\mathrm{A}$ and $\mathrm{B}$ sites due to $\mathrm{Mn}$ substitution. Significantly, along with controlled size and morphology, superparamagnetic behavior is obtained for CMFO MNPs at room temperature, which is a required feature for biomedical applications such as MRI and hyperthermia treatment. Such behavior can minimize the required nanoprobe dosage level while preventing the MNP aggregation in the dispersion resulting from magnetic dipolar interactions.

\section{ASSOCIATED CONTENT}

\section{SI Supporting Information}

The Supporting Information is available free of charge at https://pubs.acs.org/doi/10.1021/acsomega.9b02492.

Additional details of the Raman spectroscopic data analysis and theory involved along with the FE-SEM data analysis (PDF)

\section{AUTHOR INFORMATION}

\section{Corresponding Authors}

Yesh D. Kolekar - Department of Physics, Savitribai Phule Pune University, Pune 411007, India; Email: ydkolekar@ gmail.com

C. V. Ramana - Center for Advanced Materials Research (CMR), University of Texas at El Paso, El Paso, Texas 79968, United States; O orcid.org/0000-0002-5286-3065; Email: rvchintalapalle@utep.edu

\section{Authors}

Sumayya M. Ansari - Department of Physics, Savitribai Phule Pune University, Pune 411007, India

Kartik C. Ghosh - Department of Physics, Astronomy and Materials Science, Missouri State University, Springfield, Missouri 65897, United States

Rupesh S. Devan - Discipline of Metallurgy Engineering and Materials Science, Indian Institute of Technology, Indore

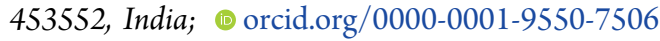

Debasis Sen - Solid State Physics Division, Bhabha Atomic Research Centre, Mumbai 400 085, India; Homi Bhabha National Institute, Mumbai 400094, India; 이이이.org/00000002-9080-0866

Pulya U. Sastry - Solid State Physics Division, Bhabha Atomic Research Centre, Mumbai 400 085, India; Homi Bhabha National Institute, Mumbai 400094, India

Complete contact information is available at:

https://pubs.acs.org/10.1021/acsomega.9b02492

\section{Notes}

The authors declare no competing financial interest.

\section{ACKNOWLEDGMENTS}

S.M.A. is thankful to BARC for providing the financial assistance (GOI-E-175) to carry out the research work. C.V.R. acknowledges with pleasure the support from National Science Foundation (NSF), USA, with NSF-PREM grant \#DMR-1827745.

\section{REFERENCES}

(1) Ansari, S. M.; Bhor, R. D.; Pai, K.; Mazumder, S.; Sen, D.; Kolekar, Y. D.; Ramana, C. V. Size and Chemistry Controlled cobaltFerrite Nanoparticles and their Anti-proliferative Effect Against the MCF-7 breast Cancer Cells. ACS Biomater. Sci. Eng. 2016, 2, 21392152.

(2) Hudson, R.; Chazelle, V.; Bateman, M.; Roy, R. C.; Li, J.; Moores, A. Sustainable Synthesis of Magnetic Ruthenium-coated Iron 
Nanoparticles and Application in the Catalytic transfer hydrogenation of ketones. ACS Sustainable Chem. Eng. 2015, 03, 814-820.

(3) Tiano, L.; Papaefthymiou, G. C.; Lewis, C. S.; Han, J.; Zhang, C.; Li, Q.; Shi, C.; Abeykoon, A. M. M.; Billinge, S. J. L.; Stach, E.; Thomas, J.; Guerrero, K.; Munayco, P.; Munayco, J.; Scorzelli, R. B.; Burnham, P.; Viescas, A. J.; Wong, S. S. Correlating size and composition-dependent effects with magnetic, Mössbauer, and Pair Distribution Function, Measurements in a Family of Catalytically Active Ferrite Nanoparticles. Chem. Mater 2015, 27, 3572-3592.

(4) Genc, S.; Derin, B. Synthesis and rheology of ferrofluids: a review. Curr. Opin. Chem. Eng. 2014, 3, 118-124.

(5) Huang, J.; Wang, L.; Lin, R.; Wang, A. Y.; Yang, L.; Kuang, M.; Qian, M.; Mao, H. Case in Coated Iron Oxide Nanoparticles for High MRI Contrast Enhancement and Efficient Cell Targeting. ACS Appl. Mater. Interfaces 2013, 5, 4632-4639.

(6) Hong, K. H.; Solana-Madruga, E.; Coduri, M.; Attfield, J. P. Complex Cation and Spin Orders in the High-pressure ferrite CoFe3O5. Inorg. Chem. 2018, 57, 14347-14352.

(7) Sosnowska, I.; Azuma, M.; Przeniosło, R.; Wardecki, D.; Chen, W.; Oka, K.; Shimakawa, Y. Crystal and Magnetic Structure in cosubstituted BiFeO3. Inorg. Chem. 2013, 52, 13269-13277.

(8) Skeete, Z.; Cheng, H.; Crew, E.; Lin, L.; Zhao, W.; Joseph, P.; Shan, S.; Cronk, H.; Luo, J.; Li, Y.; Zhang, Q.; Zhong, C. J. Design of Functional Nanoparticles and Assemblies for Theranostic Applications. ACS Appl. Mater. Interfaces 2014, 6, 21752-21768.

(9) Ansari, S. M.; Sinha, B. B.; Pai, K. R.; Bhat, S. K.; Ma, Y. R.; Sen, D.; Kolekar, Y. D.; Ramana, C. V. Controlled Surface/interface Structure and Spin Enabled Superior Properties and Biocompatibility of Cobalt Ferrite Nanoparticles. Appl. Surf. Sci. 2018, 459, 788-801.

(10) Nam, P. H.; Lu, L. T.; Linh, P. H.; Manh, D. H.; Tam, L. T. T.; Phuc, N. X.; Phong, P. T.; Lee, I. J. Polymer-coated Cobalt Ferrite Nanoparticles: Synthesis, Characterization, and Toxicity for Hyperthermia applications. New J. Chem. 2018, 42, 14530-14541.

(11) Fernandes, C.; Pereira, C.; Fernandez-garcia, M. P.; Pereira, A. M.; Guedes, A.; Pacheco, R. F.; Ibarra, A.; Ibarra, M. R.; Araujo, J. P.; Freire, C. Tailored Design of $\mathrm{Co}_{x} \mathrm{Mn}_{1-x} \mathrm{Fe} 2 \mathrm{O} 4$ Nano ferrites: a New Route for Dual Control of Size and Magnetic Properties. J. Mater. Chem. C 2014, 2, 5818-5828.

(12) Colombo, M.; Carregal-Romero, S.; Casula, M. F.; Gutierrez, L.; Morales, M. P.; Böhm, I. B.; Heverhagen, J. T.; Prosperi, D.; Parak, W. J. Biological Applications of Magnetic Nanoparticles. Chem. Soc. Rev. 2012, 41, 4306-4334.

(13) Zhang, D.; Zhou, C.; Sun, Z.; Wu, L. Z.; Tunga, C. H.; Zhang, T. Magnetically Recyclable nanocatalysts (MRNCs): a Versatile Integration of High Catalytic Activity and Facile Recovery. Nanoscale 2012, 4, 6244-6255.

(14) Ali, I. New Generation Adsorbents for Water Treatment. Chem. Rev. 2012, 112, No. 5073.

(15) Modi, K. B.; Raval, P. Y.; Shah, S. J.; Kathad, C. R.; Dulera, S. V.; Popat, M. V.; Zankat, K. B.; Saija, K. G.; Pathak, T. K.; Vasoya, N. H.; Lakhani, V. K.; Chandra, U.; Jha, P. K. Raman and Mossbauer Spectroscopy and X-ray Diffractometry Studies on Quenched Copper-ferri-aluminates. Inorg. Chem. 2015, 1, 2851-2859.

(16) Dominguez, V. L.; Hernandez, J. M.; Tejada, J.; Ziolo, R. F. Anisotropic Chemical Expansion of La1-xSrxCoO3- $\delta$. Chem. Mater. 2013, 25, 924-934.

(17) Shirsath, S. E.; Liu, X. M.; Assadi, H. N.; Younis, A.; Yasukawa, Y.; Karan, S. K.; Zhang, J.; Kim, J.; Wang, D.; Morisako, A.; Yamauchi, Y.; Lia, S. Au quantum dots engineered room temperature crystallization and magnetic anisotropy in $\mathrm{CoFe} 2 \mathrm{O} 4$ thin films. Nanoscale Horiz. 2019, 4, 434-444.

(18) Karimi, Z.; Karimi, L.; Shokrollahi, H. Non-magnetic particles used in Biomedicine: Core and Coating Materials. Mater. Sci. Eng., C 2013, 33, 2465-2475.

(19) Gallo, J.; Long, N. J.; Aboagye, E. O. Magnetic Nanoparticles as Contrast Agents in the Diagnosis and Treatment of Cancer. Chem. Soc. Rev. 2013, 42, 7816-7833.

(20) Chen, R.; Christiansen, M. G.; Anikeeva, P. Maximizing Hysteretic Losses in Magnetic Ferrite Nanoparticles via Model-driven
Synthesis and Materials Optimization. ACS Nano 2013, 7, 89909000.

(21) Shao, H.; Min, C.; Issadore, D.; Liong, M.; Yoon, T. J.; Weissleder, R.; Lee, H. Magnetic Nanoparticles and Micro NMR for Diagnostic Applications. Theranostics 2012, 2, 55-65.

(22) Sharifi, I.; Shokrollahi, H.; Amiri, S. Ferrite-based Magnetic Nanofluids used in Hyperthermia applications. J. Magn. Magn. Mater 2012, 324, 903-915.

(23) Jang, J. T.; Nah, H.; Lee, J. H.; Moon, S. H.; Kim, M. G.; Cheon, J. Critical Enhancements of MRI Contrast and hyperthermic Effects by dopant-controlled Magnetic Nanoparticles. Angew. Chem., Int. Ed. 2009, 48, 1234-1238.

(24) Karthickraja, D.; Karthi, S.; Kumar, G. A.; Sardar, D. K.; Dannangoda, G. C.; Martirosyan, K. S.; Girija, E. K. Fabrication of core-shell CoFe2O4@HAp nanoparticles: a novel magnetic platform for biomedical applications. New J. Chem. 2019, 43, 13584-13593.

(25) Gul, I. H.; Ahmed, W.; Maqsood, A. Electrical and Magnetic Characterization of Nanocrystalline Ni-Zn Ferrite Synthesis by Coprecipitation Route. J. Magn. Magn. Mater. 2008, 320, 270-275.

(26) Peddis, D.; Orru, F.; Ardu, A.; Cannas, C.; Musinu, A.; Piccaluga, G. Interparticle Interactions and Magnetic Anisotropy in Cobalt Ferrite Nanoparticles: Influence of Molecular Coating. Chem. Mater. 2012, 24, 1062-1071.

(27) Yadav, S. P.; Shinde, S. S.; Kadam, A. A.; Rajpure, K. Y. Structural, Morphological, Dielectrical, Magnetic and Impedance Properties of Co1-xMn ${ }_{x} \mathrm{Fe} 2 \mathrm{O} 4$. J. Alloys Compd. 2013, 555, 330334.

(28) Qi, X.; Wu, D. Enhancement of the Magnetostrictive Properties of Co0.9 Mn0.1 $\mathrm{Fe} 2$ O4 Synthesized by Using the Precursor Preparation Technique. J. Magn. Magn. Mater. 2008, 320, 666-670.

(29) Choi, H. N.; Baek, K. S.; Hyun, S. W.; Shim, I. B.; Kim, C. S. A study of Co Substituted Mn Ferrite, $\mathrm{Mn}(1-x) \mathrm{Co}(\mathrm{x}) \mathrm{Fe} 2 \mathrm{O} 4(\mathrm{x}=0$, 0.5, 1.0). IEEE Trans. Magn. 2009, 45, 2554-2556.

(30) Behera, A.; Kandi, D.; Sahoo, S.; Parida, K. Construction of Isoenergetic Band Alignment between CdS QDs and CaFe2O4@ ZnFe2O4 Heterojunction: A Promising Ternary Hybrid toward Norfloxacin Degradation and H2 Energy Production. J. Phys. Chem. C 2019, 123, 17112-17126.

(31) Kambale, R. C.; Shaikh, P. A.; Harale, N. S.; Bilur, V. A.; Kolekar, Y. D.; Bhosale, C. H.; Rajpure, K. Y. Structural and Magnetic Properties of $\mathrm{Co} 1-\mathrm{xMn}_{x} \mathrm{Fe} 2 \mathrm{O} 4(0 \leq \mathrm{x} \leq 0.4)$ Spinel Ferrites Synthesized by Combustion route. J. Alloys Compd. 2010, 490, 568-571.

(32) Erdemi, H.; Demir, A.; Baykal, A. Electrical Properties of Triethylene Glycol Stabilized $\mathrm{Mn}_{x} \mathrm{Co}_{1-x} \mathrm{Fe} 2 \mathrm{O} 4 \mathrm{Nanoparticles.} \mathrm{J.} \mathrm{Inorg.}$ Organomet. Polym. 2013, 23, 690-702.

(33) Köseoğlu, Y.; Alan, F.; Tan, M.; Yilgin, R.; Öztürk, M. Low Temperature Hydrothermal Synthesis and Characterization of Mn doped Cobalt Ferrite Nanoparticles. Ceram. Int. 2012, 38, 36253634.

(34) Reddy, M. P.; Zhou, X.; Yann, A.; Du, S.; Huang, Q.; Mohamed, A. M. A. Low Temperature Hydrothermal Synthesis, Structural Investigation and Functional Properties of $\mathrm{Co}_{x} \mathrm{Mn}_{1-x} \mathrm{Fe} 2 \mathrm{O} 4(0<\mathrm{x}<1)$ nanoferrite. Superlattices Microstruct. 2015, 81, 233-242.

(35) Yang, H.; Zhang, C.; Shi, X.; Hu, H.; Du, X.; Fang, Y.; Ma, Y.; $\mathrm{Wu}, \mathrm{H}$.; Yang, S. Water-Soluble Superparamagnetic Manganese Ferrite Nanoparticles for Magnetic Resonance Imaging. Biomaterials 2010, 31, 3667-3673.

(36) Pradhan, P.; Giri, J.; Samanta, G.; Sarma, H. D.; Mishra, K. P.; Bellare, J.; Banerjee, R.; Bahadur, D. J. Comparative Evaluation of Heating Ability and Biocompatibility of Different Ferrite Based Magnetic Fluids for Hyperthermia Application. J. Biomed. Mater. Res., Part B 2007, 81, No. 12.

(37) Ghosh, S.; Mitra, S. G.; Cai, T.; Diercks, D. R.; Mills, N. C.; Hynds, D. L. Alternating Magnetic Field Controlled, Multifunctional Nano-reservoirs: Intracellular Uptake and Improved Biocompatibility. Nanoscale Res. Lett. 2010, 5, No. 195. 
(38) Denton, A. R.; Ashcrof, N. W. Vegard's law. Phys. Rev. A 1991, 43, 3161-3164.

(39) Vasoya, N. H.; Lakhani, V. K.; Sharma, P. U.; Modi, K. B.; Kumar, R.; Joshi, H. H. Study on the Electrical and Dielectric Behaviour of $\mathrm{Zn}$-substituted Cobalt ferrialuminates. J. Phys.: Condens. Matter 2006, 18, 8063-8092.

(40) Atif, M.; Turtelli, R. S.; Grössinger, R.; Siddique, M.; Nadeem, M. Effect of Mn Substitution on the Cation Distribution and Temperature Dependence of Magnetic Anisotropy Constant in $\mathrm{Co}_{1-x} \mathrm{Mn}_{x} \mathrm{Fe} 2 \mathrm{O} 4(0.0 \leq \mathrm{x} \leq 0.4)$ Ferrites. Ceram. Int. 2014, 40, 471478.

(41) Manikandan, A.; Durka, M.; Antony, S. A. Role of Mn2+ Doping on Structural, Morphological, and Opto-Magnetic Properties of Spinel $\mathrm{Mn}_{x} \mathrm{Co} 1-\mathrm{xFe} 2 \mathrm{O} 4$ ( $\mathrm{x}=0.0,0.1,0.2,0.3,0.4$, and 0.5 ) Nanocatalysts. J. Supercond. Nov. Magn. 2015, 28, 2047-2058.

(42) Ratkowksy, D. A. Handbook of Nonlinear Regression Models; M. Dekker: New York, 1990.

(43) (a) Gorter, E. W. Saturation Magnetization and Crystal Chemistry of ferrimagnetic oxides. Philips. Res. Rep. 1954, 9, 321365. (b) Standley, K. J. Oxide Magnetic Materials; Oxford at the Claredon Press, 1962.

(44) Anantharamaiah, P. N.; Joy, P. A. Enhancing the strain sensitivity of $\mathrm{CoFe} 2 \mathrm{O} 4$ at low magnetic fields without affecting the magnetostriction coefficient by substitution of small amounts of $\mathrm{Mg}$ for Fe. Phys. Chem. Chem. Phys. 2016, 18, 10516-10527.

(45) Kumar, C. S. S. R. Raman Spectroscopy for Nanomaterials Characterization; Springer: Heildeberg, Germany, 2012.

(46) Foerster, M.; Iliev, M.; Dix, N.; Mart'1, X.; Barchuk, M.; $\mathrm{S}^{\prime}$ anchez, F.; Fontcuberta, J. The Poisson Ratio in CoFe2O4 Spinel Thin Films. Adv. Funct. Mater. 2012, 22, 4344-3351.

(47) Chandramohan, P.; Srinivasan, M. P.; Velmurugan, S.; Narasimha, S. V. Cation distribution and Particle Size Effect on Raman Spectrum of CoFe2O4. J. Solid State Chem. 2011, 184, 89-96.

(48) Manjon, F. J.; Tiginyanu, I.; Ursaki, V. Pressure-Induced Phase Transitions in $A B 2 X 4$ Chalcogenide Compounds, Springer-Verlag: Berlin, Heidelberg, 2014.

(49) Naik, S. R.; Salker, A. V. Change in the Magnetostructural Properties of Rare Earth Doped Cobalt Ferrites Relative to the Magnetic Anisotropy. J. Mater. Chem. 2012, 22, 2740-2750.

(50) Laha, S. S.; Regmi, R.; Lawes, G. Structural Origin for Lowtemperature Relaxation Features in Magnetic Nanoparticles. J. Phys. D: Appl. Phys. 2013, 46, No. 325004.

(51) Rashid, N. A.; Haw, C.; Chiu, W.; Khanis, N. H.; Rohaizad, A.; Khiew, P. S.; Rahman, S. A. Structural- and Optical-properties Analysis of Single Crystalline Hematite ( $\alpha$-Fe2O3) Nanocubes Prepared by One-pot Hydrothermal Approach. Cryst. Eng. Comm. 2016, 18, 4720-4732.

(52) D’Ippolito, V.; Andreozzi, G. B.; Bersani, D.; Lottici, P. P. Raman Fingerprint of Chromate, Aluminate and Ferrite Spinels. J. Raman Spectrosc. 2015, 46, 1255-1264.

(53) Carta, D.; Casula, M. F.; Falqui, A.; Loche, D.; Mountjoy, G.; Sangregorio, C.; Corrias, A. A Structural and Magnetic Investigation of the Inversion Degree in Ferrite Nanocrystals MFe2O4 $(\mathrm{M}=\mathrm{Mn}$, Co, Ni). J. Phys. Chem. C 2009, 113, 8606-8615.

(54) Varshney, D.; Verma, K.; Kumar, A. Substitutional Effect on Structural and Magnetic Properties of AxCo1-xFe2O4 (A = Zn, Mg and $\mathrm{x}=0.0,0.5)$ Ferrites. J. Mol. Struct. 2011, 1006, 447-452.

(55) Scheffe, J. R.; Allendorf, M. D.; Coker, E. N.; Jacobs, B. W.; Daniel, A. H. M.; Weimer, A. W. Hydrogen Production via Chemical Looping Redox Cycles Using Atomic Layer Deposition-Synthesized Iron Oxide and Cobalt Ferrites. Chem. Mater. 2011, 23, 2030-2038.

(56) Pązik, R.; Piasecka, E.; Małecka, M.; Kessler, V. G.; Idzikowski, B.; Sniadecki, Z.; Wiglusz, R. J. Facile Non-hydrolytic Synthesis of Highly Water Dispersible, Surfactant Free Nanoparticles of Synthetic $\mathrm{MFe} 2 \mathrm{O} 4(\mathrm{M}-\mathrm{Mn} 2+, \mathrm{Fe} 2+, \mathrm{Co} 2+, \mathrm{Ni2}+)$ Ferrite Spinel by a Modified Bradley reaction. RSC Adv. 2013, 3, 12230-12243.

(57) Yu, T.; Tan, S. C.; Shen, Z. X.; Chen, L. W.; Lin, J. Y.; See, A. K. Structural Study of refractory-metal-free $\mathrm{C} 40 \mathrm{TiSi} 2$ and its Transformation to C54 TiSi2. Appl. Phys. Lett. 2002, 80, No. 2266.
(58) Nongjai, R.; Khan, S.; Asokan, K.; Ahmed, H.; Khan, I. Magnetic and Electrical Properties of In doped Cobalt ferrite Nanoparticles. J. Appl. Phys. 2012, 112, No. 084321.

(59) Ansari, S. M.; Sinha, B.; Phase, D.; Sen, D.; Sastry, P. U.; Kolekar, Y. D.; Ramana, C. V. Particle Size, Morphology, and Chemical Composition Controlled $\mathrm{CoFe} 2 \mathrm{O} 4$ Nanoparticles with Tunable Magnetic Properties via Oleic Acid Based Solvothermal Synthesis for Application in Electronic Devices. ACS Appl. Nano Mater. 2019, 2, 1828-1843.

(60) Singh, J. P.; Srivastava, R. C.; Agrawala, H. M.; Kumar, R. Micro-Raman Investigation of Nanosized Zinc Ferrite: Effect of Crystallite Size and Influence of Irradiation. J. Raman Spectrosc. 2011, 42, 1510-1517.

(61) Ahlawat, A.; Sathe, V. G. Raman study of NiFe2O4 Nanoparticles, Bulk and Films: Effect of Laser Power. J. Raman Spectrosc. 2011, 42, 1087-1094.

(62) Sahoo, S.; Dhara, S.; Mahadevan, S.; Arora, A. K. J. Nanosci. Nanotechnol. 2009, 9, No. 564.

(63) Guinier, A.; Fournet, G.; Walker, B. C.; Yudowith, L. K. Small Angle Scattering of X-rays, Wiley: New York, 1955.

(64) Glatter, O.; Kratky, O. Small Angle X-ray Scattering; Academic Press: New York, 1982.

(65) Aitchison, J.; Brown, J. A. C. The Lognormal Distribution; Cambridge University Press: Cambridge, U.K., 1957.

(66) Sorensen, C. M.; Cai, J.; Lu, N. Test of Static Structure Factors for Describing Light Scattering from Fractal Soot Aggregates. Langmuir 1992, 8, 2064-2069.

(67) Sorensen, C. M.; Wang, G. M. Size Distribution effect on the Power law Regime of the Structure Factor of Fractal Aggregates. Phy. Rev. E 1999, 60, 7143-7148.

(68) Kolekar, Y. D.; Sanchez, L. J.; Ramana, C. V. Dielectric Relaxations and Alternating Current Conductivity in Manganese Substituted Cobalt Ferrite. J. Appl. Phys. 2014, 115, 1-12.

(69) Lin, C. R.; Chu, Y. M.; Wang, S. C. Magnetic Properties of Magnetite Nanoparticles Prepared by Mechanochemical Reaction. Mater. Lett. 2006, 60, 447-450.

(70) Salunkhe, A. B.; Khot, V. M.; Phadatare, M. R.; Thorat, N. D.; Joshi, R. S.; Yadav, H. M.; Pawar, S. H. Low Temperature Combustion Synthesis and Magnetostructural Properties of $\mathrm{Co}-\mathrm{Mn}$ Nanoferrites. J. Magn. Magn. Mater. 2014, 352, 91-98.

(71) Bhame, S. D. Structural, Magnetic and Magnetostrictive Properties of Substituted Lanthanum Manganites and Spinel Ferrites. Ph.D. Thesis; University of Pune: Maharashtra: India, 2007.

(72) Kim, C. H.; Myung, Y.; Cho, Y. J.; Kim, H. S.; Park, S. H.; Park, J. Electronic Structure of Vertically Aligned Mn-doped CoFe2O4 Nanowires and their Application as Humidity Sensors and Photodetectors. J. Phys. Chem. C. 2009, 113, No. 7085.

(73) Yang, C. N.; Chinnasamy, J. M.; Greneche, Y.; Chen, Y.; Yoon, S. D.; Chen, Z.; Hsu, K.; Cai, Z.; Ziemer, K.; Vittoria, C.; Harris, V. G. Enhanced Neel Temperature in Mn Ferrite Nanoparticles Linked to growth-rate-induced Cation Inversion. Nanotechnology. 2009, 20, No. 185704.

(74) Ranvah, N.; Melikhov, Y.; Nlebedim, I.; Jiles, D. C.; Snyder, J. E.; Moses, A. J.; Williams, P. I.; Anayi, F. Temperature Dependence of Magnetic Anisotropy of Germanium/cobalt co-Substituted Cobalt Ferrite. J. Appl. Phys. 2009, 105, No. 07A518.

(75) Paulsen, J. A.; Ring, A. P.; Lo, C. C. H.; Snyder, J. E.; Jiles, D. C. Manganese Substituted Cobalt Ferrite Magnetostrictive Materials for Magnetic Stress Sensor Applications. J Appl. Phys. 2005, 97, No. 044502.

(76) Smith, J.; Wijn, H. P. J. Ferrites, Philips Technical Library: London, 1959.

(77) Jun, Y. W.; Lee, J.-H.; Cheon, J. Chemical Design of Nanoparticle Probes for High-Performance Magnetic Resonance Imaging. Angew. Chem., Int. Ed. 2008, 47, 5122-5138.

(78) Ammar, S.; Helfen, A.; Jouini, N. Magnetic Properties of Ultrafine Cobalt Ferrite Particles Synthesized by Hydrolysis in a Polyol Medium. J. Mater. Chem. 2001, 11, 186-192. 
(79) Bozorth, R. M.; Tilden, E. F.; Williams, A. J. Anisotropy and Magnetostriction of Some Ferrites. Phys. Rev. 1955, 99, 1788-1799.

(80) Iglesias, O.; Labarta, A.; Batlle, X. Exchange bias Phenomenology and Models of Core/shell Nanoparticles. J. Nanosci. Nanotechnol. 2008, 8, 2761-2780.

(81) Cullity, B. D.; Graham, C. D. Introduction to Magnetic Materials; Wiley IEEE Press, 2009.

(82) Ślawska-Waniewska, A. S.; Didukh, P.; Greneche, J. M.; Fannin, P. C. Mossbauer and Magnetization Studies of CoFe2O4 Particles in a Magnetic Fluid. J. Magn. Magn. Mater. 2000, 215-216, 227-230.

(83) Köseoğlu, Y.; Kavas, H. Size and Surface Effects on Magnetic Properties of Fe3O4 Nanoparticles. J. Nanosci. Nanotechnol. 2008, 8, 584-590.

(84) Köseoğlu, Y.; Kavas, H.; Aktas, B. Surface effects on Magnetic Properties of Superparamagnetic Magnetite Nanoparticles. Phys. Status Solidi A 2006, 203, 1595-1601.

(85) Kodama, R. H.; Berkowitz, A. E.; McNiff, E. J., Jr.; Foner, S. Surface Spin Disorder in NiFe2O4 Nanoparticles. Phys. Rev. Lett. 1996, 77, 394-397.

(86) Coey, J. M. D. Noncollinear Spin Arrangement in Ultrafine Ferrimagnetic Crystallites. Phys. Rev. Lett. 1971, 27, 1140-1142.

(87) Jovanović, S.; Spreitzer, M.; Tramsek, M.; Trontelj, Z.; Suvorov, D. Effect of Oleic Acid Concentration on the Physicochemical Properties of Cobalt ferrite Nanoparticles. J. Phys. Chem. C 2014, 118, 13844-13856.

(88) Stoner, E. C.; Wohlfarth, E. P. A Mechanism of Magnetic Hysteresis in Heterogeneous Alloys. Philos. Trans. R. Soc., A 1948, 240, 599-642.

(89) Pacakova, B.; Mantlikova, A.; Niznansky, D.; Kubickova, S.; Vejpravova, J. Understanding Particle Size and Distance Driven Competition of Interparticle Interactions and Effective Single-particle Anisotropy. J. Phys.: Condens. Matter. 2016, 28, No. 206004. 